\title{
TABLES FOR THE CALCULATION OF THE INDUC- TANCE OF CIRCULAR COILS OF RECTANGULAR CROSS SECTION
}

\author{
By Frederick W. Grover
}

\begin{abstract}
Multilayer coils with spaced layers or banked or honeycomb windings for reducing the capacity of the coil find an extensive use in radio circuits where a greater inductance is required than can readily be obtained from a single-layer coil.

The inductance of these varied types of multilayer coil may be accurately calculated from the known formulas for the inductance of circular coils of rectangular cross section, provided a relatively small correction is applied to take into account the fact that a part of the cross section is occupied by insulation.

These formulas (the most important of which are given in the appendix for reference) are rather complicated, calculations made by them are time consuming, and some uncertainty is often experienced in making a choice of the most suitable formula for a given case. When many calculations have to be made, there is an imperative need for some means for simplifying the calculations and for rendering unnecessary a choice among formulas.

Such aids which have previously appeared have taken the form of a single empirical formula to cover the whole range of coils, or of charts from which the inductance, or some function simply related to the inductance, can be interpolated. These methods do not allow of an accuracy greater than about I per cent at best, and in some instances the curves have been based on unsuitable formulas and give only a rough accuracy.

Tables are presented in this paper which are based on accurate formulas for the inductance. By the use of these tables the calculation of the inductance is reduced to the simplest of arithmetical operations. The tabulated values give directly an accuracy in the value of the inductance of one part in ten thousand. In the case of the most unfavorable interpolation the error should not be as great as a part in a thousand.

Examples are given to illustrate and explain the use of the tables, and the further application of the tables to the calculation of mutual inductance in certain cases is treated.
\end{abstract}

CONTENTS Page

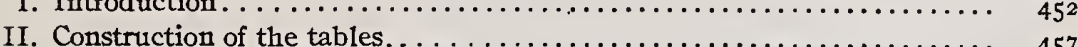

III. Calculation of the dimensions of the equivalent coil, calculation of the correction for insulation . . . . . . . . .

IV. Special cases and examples. . . . . . . . . . . . .

I. Circular coils wound with round or rectangular sectioned wire in rectangular channels . . . . . . . . . . . . . . . . . . . . . . . .

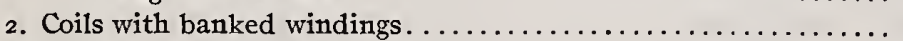

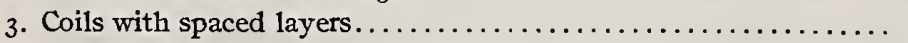

5. Solenoids wound with strip or large round wire ........... 467

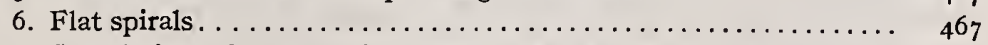

7. Calculation of mutual inductance of coils of rectangular cross section having the same length or the same mean radius and thickness. Application to the calculation of the leakage react-

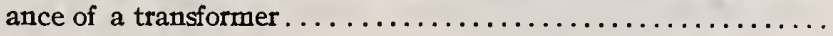


V. Summary of principal formulas-Interpolation formula . . . ...........

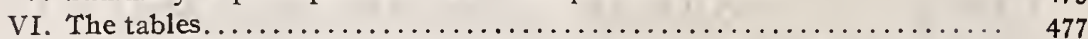

Table 1 .- Values of constants $K^{\prime}, k, P^{\prime}$, and $f$ for use in formulas 2 and $4 . \quad 477$

Table 2.-Values of Nagaoka's constant $K$ for use in formula $2 \ldots . . \quad 480$

Table 3.-Values of the quantity $P$ for use in formula 4 and for disk coils of negligible thickness.................. $48 \mathrm{r}$

Table 4.-Constants for insulation correction for flat spirals....... $48 \mathrm{r}$

Table 5.-Binomial coefficients for interpolation by differences..... 482

VII. Appendix-Collection of formulas used in the preparation of the tables. $\quad 482$

Lyle's formula for short, thin coils................... 482

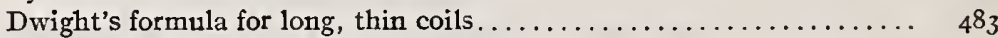

Dwight's formula for long, thick coils.................. 484

Butterworth's formulas for thick coils................... $44_{5}$

Lyle's formula for narrow disk coils . . . . . . . . . . . . . . 487

Spielrein's formula for wide disk coils.................. 487

\section{INTRODUCTION}

Although single-layer coils or solenoids recommend themselves for use in radio work on account of the ease with which they may be wound, the smallness of their capacity, and the accuracy with which their inductance may be calculated, they have the disadvantage that their inductance is of necessity less than that offered by some other styles of winding. For cases where a large inductance is required, the use of multiple-layer coils is natural. Such a coil, wound layer upon layer in a rectangular channel, is easy to prepare and is in general satisfactory for low-frequency work. Coils of this form are, however, not suitable for high-frequency circuits on account of the large capacity between layers. To reduce this capacity, means must be found either to reduce the potential between adjacent turns in different layers or to increase the distance between layers. The first method is employed in coils prepared with a so-called "banked winding," in which the wire is so carried as to achieve the winding of several layers simultaneously. The alternative method of separating the layers is governed by the consideration that the capacity between parallel wires falls off in proportion to the logarithm of the ratio of distance between centers to the diameter of the wire. Thus a small separation between wires brings about a very appreciable reduction of capacity, but beyond a moderate separation little is gained. In one form of coil making use of this principle the turns of one layer are held away from those of the adjoining layers by thin pieces of insulation of perhaps one or two millimeters in thickness. In the type of coil known as "honeycomb" coils the wire is carried diagonally back and forth across the cross section while it is being wound,

\footnotetext{
${ }_{1}^{1}$ Bureaus of Standards Circular No. 74 , p. 136.
} 
with the result that only after the completion of two or more complete layers does the wire run parallel and directly above a preceding turn of wire. Thus the centers of two wires which run parallel to one another are separated by at least twice the diameter of the covered wire. The recent type of coil known as "duolateral" (Giblin, U. S. Patent No. I342209) is to be regarded as a modification of the "honeycomb" form.

An examination of the above types of multiple-layer coils shows that the current distribution in the cross section is essentially the same as that of a simple circular coil of rectangular cross section, and the inductance may therefore be calculated by the same formulas as apply to the latter case, provided that an appropriate correction be made for the space occupied by the insulation.

Formulas for calculating the inductance of circular coils of relatively small rectangular cross section, as compared with the mean radius of the coil, have been known for many years. Of these, that of Perry ${ }^{2}$ is empirical and of no great accuracy. Maxwell's ${ }^{3}$ formula replaces the coil by two circular filaments of radii equal to the mean radius of the coil, separated by a distance equal to the geometric mean distance of the points of the rectangular cross section. The inductance of the coil is assumed equal to the mutual inductance of these filaments, multiplied by the square of the number of turns. This method gives good results when the cross section is small compared to the mean radius, but fails for cases where the distance between the filaments is so great that their curvature can not be neglected.

A more accurate formula was obtained by Weinstein, ${ }^{4}$ who integrated Maxwell's series formula for the mutual inductance of unequal coaxial circular filaments, ${ }^{5}$ not very far apart, over the cross section of the coil. Stefan ${ }^{6}$ in the very same year gave an equivalent expression in which certain terms of Weinstein's formula are combined. Their values may be obtained from a table given in his original article, and since extended ${ }^{7}$ by the author of the present paper to cover the case of "pancake" coils. The Stefan-Weinstein formula is well known and has been much used. It gives very accurate values for coils where the diagonal of the cross section is not greater than the mean radius of the coil, but for larger cross sections the neglected terms of higher order become important.

${ }^{2}$ Phil. Mag., 30, p. 223; 1890

3 Electricity and Magnetism, 2, Sec, 706.

Ann. der Phys., 257, p. 329; 1884.
Electricity and Magnetism, 2, Sec 705.

Ann. d. Phys., 258, p. $113 ; 1884$

B. S. Sci. Papers, No. 320, p. 556; rgr8. 
A useful formula for coils of larger cross section was developed by Rosa ${ }^{8}$ who imagined the cross section of the coil to be divided up into squares. The coil is compared with a cylindrical current sheet having the same radius as the mean radius of the coil. Each of the square elements of the coil cuts from the cylindrical current sheet an element whose cross section is a straight line. The self-inductance of each element of the coil is different from the self-inductance of the corresponding element of the current sheet, and the mutual inductance of each pair of the elements of the coil is different from the mutual inductance of the corresponding elements of the current sheet. The total difference in the inductances of coil and current sheet will be found by summing up these differences for the elements. Rosa's method takes account of the difference in self-inductances in a term $A_{\mathrm{s}}$ and the difference in mutual inductances by a term $B_{\mathrm{s}}$, which he tabulated for a useful range of coils likely to occur in practice. ${ }^{9}$ These correction terms were obtained from the values of the geometrical mean distances of squares and straight lines. The values thus found are exact when the radius of the coil is infinite (case of straight bars), and the error due to the curvature of the wires is negligible for coils of small cross-sectional dimensions, compared with the mean radius. Only relatively thin coils of moderate length are covered by the tables given for $A_{\mathrm{s}}$ and $B_{\mathrm{s}}$, and for these the errors of the method are unimportant.

The case of longer coils was treated by Butterworth, ${ }^{10}$ who developed a formula for the effect of the cross section, which is very accurate when the winding is thin. A similar formula, which is, however, somewhat more convergent than Butterworth's, has been developed by Dwight. ${ }^{11}$

A formula suitable for coils of larger cross sections was published by Lyle in I $914 .{ }^{12}$ The method followed was that of Weinstein, the integration being extended to include terms in the sixth power of the ratios of the cross-sectional dimensions to the radius. Tables given by Lyle in the original paper and still further extended in a communication to the author of the present paper ${ }^{13}$ render it a simple matter to obtain the inductance for coils in which the diagonal of the cross section is as great as twice the mean radius.

\footnotetext{
${ }^{8}$ B. S. Bulletin, 4, p. 369 , I907, and B. S. Sci. Papers, No. I69, p. 138; rgr 2 .

9 B. S. Sci. Papers, No. I69, p. 200; I912.

10 Proc. Phys. Soc. London, 27, p. 371 ; 1915.

11 Trans. Am. Inst. Ellec. Engr., 38, Part 2, p. 1675, formula 13; r9rg.

12 Phil. Trans., 213A, p. 421; 19I4.

13 B. S. Sci. Papers, No. 320, p. 557; 19r8.
} 
The only formulas which have appeared for coils of very large cross sections are those of Dwight and Butterworth. Dwight ${ }^{14}$ covers the case of very thick coils, including the case where the inner radius is zero, in the form of a series formula, which is, however, good only for coils whose length is greater than about twice the mean diameter. Butterworth ${ }^{15}$ gave a general treatment of the case of thick coils with inner radius zero, which he calls "solid coils." By combining the mutual inductances of two or more pairs of solid coils the inductance of any thick coil whatever may be accurately treated. As might be expected, these valuable formulas are somewhat formidable in appearance, and although not really difficult to use are not likely to be generally employed without tables to abridge the necessary calculations. They have, however, proved to be invaluable in the present work.

With so many formulas of overlapping ranges available, it is possible to calculate accurately the inductance of any circular coil of rectangular cross section, whatever the relations between its dimensions. If only an occasional computation is to be made, doubt is likely to arise as to the choice of the proper formula; if many computations are to be made, the labor necessarily becomes considerable. For these reasons, and because of the increasing importance of such inductance calculations, tables which simplify the work and render discrimination between the formulas unnecessary should find extensive use.

Among previous attempts to fill such a want may be mentioned the work of Brooks and Turner, ${ }^{16}$ who developed an empirical formula for which an accuracy of better than 3 per cent is claimed for all cases, and the charts of Eccles, ${ }^{17}$ Lowey, ${ }^{18}$ and Doggett, ${ }^{19}$ which seem to be of rather limited application for accurate work. Especial mention should be made of curves published recently by Coursey, ${ }^{20}$ which give the inductance very simply for coils of square cross section and for coils where the length of the coil is greater than the thickness of the winding. Although pancake coils are not included, attention is called to the very small difference between the inductances of two coils having the same mean radius, the length of one coil being equal to the thickness of the winding of the other, and vice versa. It is to be regretted that in the reproduction of Coursey's curves only the main divisions

\footnotetext{
${ }^{14}$ Electrical World, 21, p. 300 , formula 5; 1918.

15 Phil Mag., 29, p. 578; 1915.

${ }^{16}$ Bulletin No. 53, Univ, of Illinois Engr. Experiment Station, 1912.
}

\author{
${ }^{17}$ Handbook of Wireless Telegraphy. \\ 13 Wireless World, 3, p. 664; 1916. \\ ${ }^{19}$ Electrical World, 63, p. 259; Jan, 3I, 1914. \\ ${ }^{20}$ Proc. Phys. Soc. London, 31, p. I5s; Igrg.
}


of the cross-section paper have been retained. Because of this, readings can not be taken with certainty closer than to I per cent of the value of the inductance. In obtaining the correction for the cross section of the winding Coursey made use of Rosa's method, described above, obtaining values of $A_{\mathrm{s}}$ and $B_{\mathrm{s}}$ by calculation for cases not already covered by Rosa's table. This method gives results which are more accurate than is necessary for the curves for all lengths of coils whose thickness of winding is not greater than about one quarter of the mean diameter of the coil. For thicker coils the error due to the neglect of the curvature of the wires already discussed above begins to be appreciable, being especially noticeable with the longer coils, and for the thickest coils Coursey's values are in error due to this cause by amounts which steadily increase with the length of the coil from less than I per cent for a square cross section up to values which reach as much as 25 per cent of the true value of the inductance for long "solid" coils, the true value being greater than that given by the curves.

For an accuracy of I per cent the curves published by Dwight ${ }^{21}$ are very convenient. These are based on Lyle's formula for the shorter coils and on Dwight's formulas (see appendix) for the longer coils. The range of lengths is from disk coils up to those whose length is six times the mean diameter.

The present paper has for its object the presentation of tables for facilitating the calculations of the inductance of coils of rectangular cross section, with an accuracy of better than one part in a thousand in the most unfavorable case. For this purpose tables have been chosen rather than curves because of the difficulty of reproduction of the latter without loss of accuracy, and also because, for the most part, satisfactory interpolation can be made from the tables using only first and second differences. It is, of course, an easy matter to prepare curves plotted from the data of the tables in cases where this may seem desirable, and suggestions are given below for the plotting of such curves. These tables have been prepared from the results of calculations based upon the accurate formulas already described, which are given for reference in the appendix in case more accurate values

\footnotetext{
21 Trans. Am. Inst. Elec. Engr., 38 , Part 2, p. 1675; 1919. Note added Oct. 14, 1922. While the present paper was in press a second article by Dwight has appeared in the Electrical Journal for June, I922. In this are given curves for obtaining $\frac{L b}{\sqrt{2}^{2} a^{2}}$. The curves are plotted with the ratios $\frac{b}{2 a}$ and $\frac{c}{2 a}$ as parameters

and with the dimensions in inches. The reproduction of the curves is such that values may be read to a part in a thousand if care is taken. Values of $\underline{b}$ up to 25 are covered.
} 
should be required than can be obtained from the tables. Each value in the table was obtained from that one of these formulas which gave the best convergence for the case in question, and for those cases where two formulas were available checks have been obtained. Excepting for the rare cases where the order of accuracy of the tables may not suffice, the inductance may be obtained from the tables by the simplest of calculations, and in most instances a calculation by an alternative formula from another entry in the tables will supply a check on the first calculation.

\section{CONSTRUCTION OF THE TABLES}

The inductance of a single-layer coil may be written as

$$
L_{\mathrm{s}}=0.002 \pi^{2}\left(\frac{2 a}{b}\right) n^{2} a K \text { microhenries, }
$$

in which $a=$ the mean radius of the winding in centimeters, $b=$ the length of the coil in centimeters, $n=$ the number of turns, and $K$ is a factor which is a function of the ratio $\frac{2 a}{b}=\frac{\text { mean diameter }}{\text { length }}$ alone. A very complete table of values of $K$ was calculated
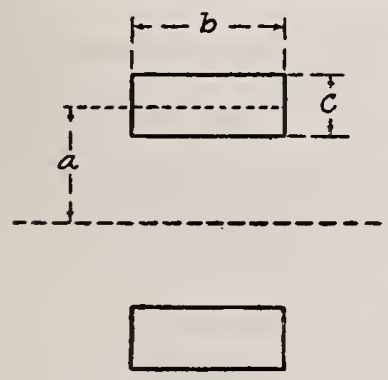

FIG. I.-Dimensions used for calculating inductance of multiple-layer coil of rectangular cross section and prepared by Nagaoka, ${ }^{22}$ and has been included here (Table 2) for convenience. For very long coils $K$ approaches unity, in which case the formula (I) gives the well known formula for the inductance of an infinitely long solenoid. For very short coils $K$ approaches zero.

The inductance of a coil of rectangular cross section, of mean radius $a$, of length $b$, and of thickness $c$ (see Fig. I), is less than that of the single-layer coil of the same mean radius and same length, provided the single-layer coil has the same number of turns. To take into account the effect of the cross section, we may write, following Coursey, ${ }^{23}$

$$
\begin{gathered}
L_{\mathrm{u}}=0.002 \pi^{2}\left(\frac{2 a}{b}\right) n^{2} a(K-k), \\
L_{\mathrm{u}}=0.002 \pi^{2}\left(\frac{2 a}{b}\right) n^{2} a K^{\prime} \text { microhenries, }
\end{gathered}
$$

20 J. College of Science, Tokyo, 27, Art. 6, p. 18; 1909.

28 Proc. Phys. Soc. London, 31, p. 159, 162; 1919.

$102575^{\circ}-22-2$ 
in which $L_{\mathrm{u}}$ is the inductance, supposing that the current is distributed uniformly over the rectangular cross section, and $K^{\prime}$ is a factor which depends upon the ratio $\frac{2 a}{b}$ and also on the dimensions of the cross section. The quantity $k$ shows how much less the factor $K^{\prime}$ is than the value $K$ (for the single-layer coil with the same ratio $\frac{2 a}{b}$ ) as a result of the spreading of the current over the rectangular cross section. Calculated values of both $k$ and $K^{\prime}$ are given in Table $\mathrm{I}$. In Dwight's curves the quantity $2.54 \pi^{2} \mathrm{~K}^{\prime} \mathrm{IO}^{-9}$ is plotted. Coursey gives both $K^{\prime}$ and $k$.

Instead of using the formula for the inductance of the single-layer coil as a basis we may choose also the formula for the inductance of a very thin disk.

$$
L_{\mathrm{s}}=0.00 \mathrm{I} n^{2} a P \text { microhenries, }
$$

in which the mean radius is $a$ as before, while $c$ is the width of the disk; that is, the difference of the inner and outer radii (see Fig. 2). If the disk is negligibly thin, the dimension $b$ of Figure $\mathrm{I}$ is zero, and the inductance given by $(3)$ is that of a current sheet. The factor $P$ is a function of the ratio $\frac{c}{2 a}=$ thickness divided by mean diameter A formula applicable to small values of this ratio was derived by Rayleigh and Niven ${ }^{24}$ (formula 70, B. S. Sci. Papers, No. I69), and was extended by Lyle. ${ }^{25}$ The case of relatively wide disks was very completely treated by Spielrein ${ }^{26}$ who tabulated values for a number of values of $\frac{c}{2 a}$. Table 3 has been calculated by the author of this paper and gives the value of $P$ for all possible values of $\frac{c}{2 a}$ in steps of o.or.

To calculate the inductance of a coil of rectangular cross section we write

$$
L_{\mathrm{u}}=0.001 n^{2} \text { aP } f=0.001 n^{2} a P^{\prime} \text { microhenries, }
$$

in which $P$ is the factor for the disk having the same values of $c$ and $a$, and $f$ is a factor less than unity, which takes into account the reduction of the inductance due to the distribution of the current

\footnotetext{
24 Proc. Roy. Soc, 32, p. I04; I88I.

${ }_{25}$ Phil. Trans., A, 213, p. 42I; I9I4. See B. S. Sci. Papers, No. 320, D. 554, formula 70A.

${ }^{20}$ Archiv für Elektrotechnik, 3, p. I $\varepsilon_{7}$; Igr5. See B. S. Sci. Papers, No. 320, p. 555, formula 24 A.
} 
over the rectangular cross section. Values of $f$, and $P^{\prime}=P f$ are given in Table 3 .

The formula (4) has the advantage of great simplicity and is especially suitable for short, thick coils (disk coils or pancake

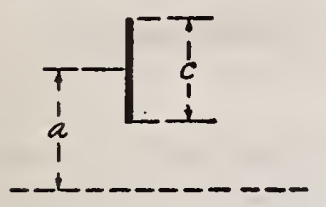

1

FIG. 2.-Disk element of multiple-layer coil of rectangularcross section coils), whereas formula (2) is especially adapted to long coils. For the majority of cases, however, either formula may be used, in conjunction with Table I, and by using both a valuable check on the calculation is afforded.

Formulas(2) and (4) are written in such a form as to express the inductance directly in terms of the number of turns, and the mean radius.

Thus written, the other dimensions enter only in pairs, as simple ratios. In any given case two of these ratios or parameters are involved, so that the tables have to be constructed with two arguments. Of the possible values $\frac{2 a}{b}, \frac{b}{2 a}, \frac{c}{2 a}, \frac{2 a}{c}, \frac{b}{c}$ and $\frac{c}{b}$ it has seemed most convenient for purposes of interpolation to choose the pairs $\frac{c}{2 a}, \frac{c}{b}$ or $\frac{c}{2 a}, \frac{b}{c}$ for long and short coils, respectively. ${ }^{27}$ The values of $K^{\prime}, k, P^{\prime}$, and $f$ in Table $\mathrm{I}$ were calculated for these parameters, making use of the most convergent of the formulas available in each case and where possible a check formula. The tabulated values are sufficiently accurate to allow of an accuracy of one part in ten thousand in the final inductance for values taken directly from the tables. On account of the number of values which have had to be calculated it is possible that errors may be found or misprints may creep in. The author will be grateful for information regarding any errors which may be detected.

Table I is constructed for values of $\frac{c}{2 a}$ in steps of o. I from $\frac{c}{2 a}$ $=0 . \mathrm{I}$ to $\frac{c}{2 a}=\mathrm{r}$, with the additional values 0.025 and 0.05 . For $\frac{c}{2 a}=0$ we have the case of a solenoid, and formula (I) and Table 2 are to be used. The other extreme is that of $\frac{c}{2 a}=\mathrm{I}$, whicli is the

\footnotetext{
${ }^{27}$ Dwight and Coursey have used the parameters $\frac{c}{2 a}, \frac{b}{2 a}$. The choice of $\frac{c}{b}$ for long coils and $\frac{b}{c}$ for short coils instead of $\frac{b}{2 a}$ makes possible the covering of the whole range of possible coils without inconvenient extension of the scale of the curves.
} 
case of a coil of zero inner radius. For each value of $\frac{c}{2 a}$, values of $\frac{c}{b}$ and $\frac{b}{c}$ in steps of o.I from zero to unity are included. When $\frac{c}{b}=0$ we have a coil of infinite length, and $\frac{b}{c}=0$ refers to a disk of negligible thickness.

For values of the arguments not included in the tables it will be necessary to make an interpolation. In general it is better to first obtain the values of $k$ by interpolation, rather than $K^{\prime}$, since for long coils, where formula (2) is especially useful, $k$ changes only very slowly, and may be easily interpolated from Table $I$. Since, furthermore, $K$ may be interpolated very accurately from Table $2, K^{\prime}$ can be calculated accurately as the difference of these quantities. The value of $\frac{2 a}{b}$ for the given case is of course obtained as the quotient of $\frac{c}{b}$ by $\frac{c}{2 a}$. In making interpolation for $k$ and $K$, second, and, in some cases, third differences will need to be taken into account. This may be accomplished readily as shown in section $\mathrm{V}$.

Likewise, when short coils are in question and it is desired to obtain values of $P^{\prime}$ not included in the Table 1 , it is better to first interpolate for $f$, which changes more slowly than $P^{\prime}$, and then with the value of $P$ obtained from Table 3 the quantity $P^{\prime}$ may be calculated as the product of $P$ and $f$. Since any uncertainty in the interpolated value of $f$ enters directly into the value of the inductance, while an uncertainty of equal fractional value in $k$ does not cause so great a fractional error in $K^{\prime}$, less accurate values will be obtained by interpolating in (4) than in (2) except for coils of small axial length. In case a double interpolation is necessary the work is naturally less simple, but the same principles are to be followed. These points are illustrated below.

In calculating the inductance of very thin coils formula (4) is not very suitable, but in (2) we may use a very accurate value of $k$ interpolated from Table 1 , and $K$ is given in Table 2 . The value of $k$ is zero for $\frac{c}{2 a}=0$, whatever the value of $\frac{c}{b}$.

If it is desired to make use of graphical interpolation, or if it seems preferable for the purpose in hand to use curves instead of 
the tables, the following points may be noted. Two sets of curves will be necessary: (a) a set showing $2 \pi^{2} \frac{c}{b} K^{\prime}$ or $P^{\prime}$ as functions of $\frac{c}{b}$ or $\frac{b}{c}$ with $\frac{c}{2 a}$ as parameter, and (b) curves showing the relation between $2 \pi^{2} \frac{c}{b} K^{\prime}$ or $P^{\prime}$ and $\frac{c}{2 a}$ with $\frac{c}{b}$ or $\frac{b}{c}$ as parameter. $2 \pi^{2} \frac{c}{b} K^{\prime}$ is chosen rather than $K^{\prime}$, because the curves are more favorable for interpolation in the former case.

Where a double interpolation has to be made, it is best to make one of the interpolations from the curves and then to construct an auxiliary curve of such values, covering the desired region in which the second interpolation has to be made. If, for example, we wish $P^{\prime}$ for $\frac{c}{2 a}=0.15, \frac{b}{c}=0.25$, we may obtain from the curves the value of $P^{\prime}$ for the cases $\frac{c}{2 a}=0.1, \frac{b}{c}=0.25 ; \frac{c}{2 a}=0.2, \frac{b}{c}=0.25$; and $\frac{c}{2 a}=0.3, \frac{b}{c}=0.25$. Plotting these values to a suitable scale, the required value may be interpolated accurately.

\section{CALCULATION OF THE DIMENSIONS OF THE EQUIVA- LENT COIL, CALCULATION OF THE CORRECTION FOR INSULATION}

The problem is therefore completely covered by the use of formulas (2) and (4) and Tables I, 2, and 3. It must be remembered, however, that these calculations apply only to the case of a coil with a rectangular section in which the current is distributed uniformly throughout the cross section. In an actual coil this can never be strictly the case. There must always be insulation between the wires. In most practical cases, however, the correction is small and may be calculated with accuracy if the dimensions of the ideal coil which is equivalent to the actual coil be properly taken. In fact, in many cases the calculation for the equivalent coil will suffice. It has been shown by Rosa ${ }^{28}$ that the $b$ dimension of the cross section of the equivalent coil is found by taking the product of the number of turns per layer by the distance between centers of adjacent wires in the layer, while similarly, the $c$ dimension is equal to the product of the number

${ }^{25}$ B. S. Bulletin, 2, p. 16r, 1906 (or B. S. Sci. Papers, No. 3r). 
of layers by the distance between centers of adjacent wires in two consecutive layers. The mean radius $a$ is equal to the mean of the inner and outer radii of the equivalent coil. This is the same as the mean radius of the layers of the coil itself. With this understanding, the cross section of the equivalent coil may be imagined to consist of an array of small rectangles at the center of each of which one of the conductors of the coil is placed. The correction to apply to the inductance of the equivalent coil to obtain the inductance of the actual coil may be worked out by the formulas for the geometric mean distance of rectangles. For the case where the distance between centers of adjacent wires in consecutive layers is equal to the pitch of the winding in the layer the rectangles become squares, and if the winding be of round wires, the correction formula is that derived by Rosa ${ }^{29}$ for this case, viz:

$$
\Delta L=0.004 \pi a n\left\{\log _{e} \frac{D}{d}+0.138 \mathrm{I}+E\right\} \text { microhenries }
$$

in which $d=$ the diameter of the bare wire, $D=$ the distance between the centers of adjacent wires in the layer or in consecutive layers, $E=$ a quantity which depends upon the number of turns and their arrangement. Rosa gives the value of $E$ in certain cases. The value 0.017 will suffice in a good many instances. Only when the wires are relatively far apart will the correction (5) exceed a few tenths of $\mathrm{I}$ per cent. It is to be added to the inductance calculated for the equivalent coil.

The inductances calculated by these formulas are, of course, for steady current or for alternating current of low frequency. They take no account of skin effect. This causes a decrease in the inductance. No accurate formulas are available for the calculation of this effect in coils of this type.

More serious, however, is the effect of the coil capacity. It has been pointed out by Howe, ${ }^{30}$ Breit, ${ }^{31}$ and others, that if the coil is to be used in a resonant circuit, coupled to a source by the mutual inductance between the coil and the circuit of the source, the capacity of the coil may be regarded as acting like a capacity in parallel with the coil. That is, the resonant frequency of the circuit is given by the equation $\frac{\mathrm{I}}{\omega^{2}}=L_{0}\left(C+C_{0}\right)$, in which $\omega=2 \pi$

\footnotetext{
29 B. S. Bulletin, 3, p. 37, 1907, and B. S. Sci. Papers, No. 169 , formula (93).

so G. W. O. Howe, Proc. Phys. Soc. London, 24, p. 251-259; August, 1912. Electrician, 69, p. 490; June 28,1912 .

a G. Breit, Phys. Rev., 17, p. 650; June, 1921.
} 
times the frequency, $L_{0}$ is the inductance of the coil, $C$ the capacity of the condenser used in series with the coil, and $C_{0}$ represents the capacity of the coil. That is, the coil acts as though it had an effective inductance $L=L_{0}\left(\mathrm{I}+\frac{C_{0}}{C}\right)$ greater than the low-frequency inductance. For frequencies near the value $\omega_{0}$ given by $\frac{\mathrm{I}}{\omega^{2}}=L_{0} C_{0}$ the reactance opposed by the coil to an emf impressed outside of the coil is very great. The coil and its capacity are in parallel resonance with the rest of the circuit at this frequency, so that the coil and its capacity act like a "trap" or "filter." This frequency is said to be the natural (fundamental) frequency of the coil. However, since the coil has also a capacity with respect to the earth and its surroundings, a complete treatment of the constants of the coil is complicated. Reference may be made to papers having to do with this subject by Breit. ${ }^{32}$

The effect of absorption in the dielectric surrounding the wires of the coil in any given case is difficult to estimate. In certain cases where the absorption is large the resistance of the coil is appreciably increased thereby, but the effect on the inductance is always much less important.

\section{SPECIAL CASES AND EXAMPLES}

Special cases which may be treated by means of the formulas and tables here given may be grouped under the following general headings: (I) Circular coils wound with round or rectangular sectioned wire in rectangular channels; (2) coils with "banked" windings; (3) coils with spaced layers; (4) honeycomb coils; (5) solenoids wound with strip or large round wire; (6) flat spirals; (7) calculation of mutual inductance of coils of rectangular cross section having the same length or the same mean radius and thickness. Application to the calculation of the leakage reactance of a transformer.

These cases will be next discussed, in order, with illustrative examples. To them is related the case of a coil wound with a rectangular cross section, but whose separate turns have the shape of polygons instead of circles. Tables are to be published by the author which show how to find the radius of a circular coil which has the same inductance as the given polygonal coil. With

${ }^{32} \mathrm{G}$. Brcit, The effective capacity of pancake coils, Phil. Mag., 44, p. 729, October, x922,; and G. Breit, The effective capacity of multilayer coils, Phil. Mag., 45, p. 963-992, May, I922. 
this radius found, the inductance may be calculated by the formulas and tables here given.

\section{CIRCULAR COILS WOUND WITH ROUND OR RECTANGULAR SECTIONED WIRE IN RECTANGULAR CHANNELS}

The dimensions of the equivalent coil of rectangular cross section must first be found by the method already discussed in Section III. Having calculated the inductance of the equivalent coil by formulas (2) and (4) and the tables, the inductance may be corrected for insulation by the formula (5) if the coil is wound with round wire. If strip is used instead, the correction depends upon the geometric mean distances of rectangles, and the value will, in general, be smaller than that applying to a round wire whose bare diameter is equal to the smaller dimension of the cross section of the strip.

EXAMPLE I.-Suppose a coil of winding channel $b=c=1.5 \mathrm{~cm}$, wound closely with 15 layers of wire with i 5 turns per layer, the mean radius being $5 \mathrm{~cm}$, and diameter of the bare wire $0.08 \mathrm{~cm}$.

In this case $n=225, a=5, \frac{c}{b}=\mathrm{I}, \frac{c}{2 a}=0.15, \frac{2 a}{b}=\frac{20}{3}$. By interpolation in Table $\mathrm{I}$, we find $k=0.06584$. From Table $2, K=0.26677$, so that $K^{\prime}=0.20093$, whence by $(2), L_{u}=0.002 \pi^{2} \frac{20}{3} \cdot 5(225)^{2}$ $0.20093=6693$ microhenries.

The value of $f$, interpolated from Table $I$ is 0.7547 , and from Table 3, $P=35.06$, and formula (4) gives $L_{\mathrm{u}}=0.00 \mathrm{I}(225)^{2} 5$ (35.06) $0.7547=6697$ microhenries. The value of $K^{\prime}$ taken from Coursey's curves is 0.20 , or if his formula be used $K^{\prime}=0.2010$.

The correction for insulation as given by $(5)$ is found as follows:

$$
\begin{aligned}
\frac{D}{d}=\frac{0.10}{0.08}=\frac{5}{4}, \log _{10} \frac{5}{4}=0.0969 \mathrm{I}, \log _{\frac{e}{4}} \frac{5}{4} & =0.223 \\
\text { numerical correction term } & =0.138 \\
E & =\frac{0.017}{0.378}
\end{aligned}
$$

so that $\Delta L=0.01257$ (5) (225) $0.378=3.34$ microhenries. Using the mean of the values of $L_{\mathrm{u}}$ found by the two methods, $L=6695+$ $3 \cdot 3=6698$ microhenries. The correction could in this case have been neglected for most kinds of work.

EXAMPLE 2.-As an example of a long coil of small winding depth we may consider the case of a winding of 400 turns, wound 
in one layer with a mean radius of $10 \mathrm{~cm}$, the winding pitch being $0.1 \mathrm{~cm}$, and the diameter of the bare wire being $0.05 \mathrm{~cm}$. This can, of course, be solved by formula (I) for a single-layer coil. The value of $K$ being $0.8 \mathrm{I} 8 \mathrm{I}, L_{\mathrm{u}}=\mathrm{I} 2919$ microhenries and, with the correction to reduce from the current sheet to a winding of round wires, $L=\mathrm{I} 2909$ microhenries.

The equivalent coil of rectangular cross section has $b=400 \times 0 . I=40$, and $c=0 . I$ (supposing each wire to stand at the center of a square composing the equivalent coil). The value of $\frac{c}{2 a}$ is here only 0.005 , which lies outside the range of Table $\mathrm{I}$. Remembering that $k=0$ for all values of $\frac{c}{b}$ when $\frac{c}{2 a}=0$, it is easy to interpolate in Table $\mathrm{I}$ and find that for this case $k=0.0033$. The same value is obtained by (I4) in the appendix, and also by Coursey's method. Accordingly with $K=0.818 \mathrm{r}, K^{\prime}=0.8 \mathrm{r} 48$, and therefore from (2) we find $L_{\mathrm{u}}=\mathrm{I} 2867$ microhenries. The correction for the insulation, calculated by (5) is 43 microhenries, so that the inductance of the coil is 12910 microhenries, which agrees closely with the values above calculated by the solenoid formula.

EXAMPLE 3.-Take the case of a thicker, longer coil. Let $c=5, a=5, b=50$. From Table I we find for $\frac{c}{2 a}=0.5, \frac{c}{b}=0 . \mathrm{I}$, $K^{\prime}=0.6717 . \quad$ For this case $\frac{b}{2 a}=5$, and the value given by Coursey's curves is $K^{\prime}=0.625$, which is 7 per cent too small. The inductance in this case is by (2), $L_{u}=0.0663 n^{2}$. By (4) we find from Table I, $P^{\prime}=2.65^{2}$, which gives the same value for $L_{\mathrm{u}}$ to the fourth place of decimals.

\section{COILS WITH BAINKED WINDINGS}

This case is treated by finding the dimensions of the equivalent coil by exactly the same method as already treated above. The order of the turns has no effect on the low-frequency inductance calculated by the formulas here.

\section{COILS WITH SPACED LAYERS}

For such coils thin spacing pieces of insulation are placed so as to hold the layers a few millimeters apart. The method of calcu$102575^{\circ}-22-3$ 
lation in this case does not differ from the preceding, except that the correction for insulating space will be more important. (See Sec. III.)

\section{HONEYCOMB COILS}

[See O. C. Roos, Wireless Age, July, August, October, November, December, 1920; R. F. Gowen, British Patent I41344.1

The inductance of this type of coil may be calculated by the same formulas as are used for multiple-layer coils wound in a rectangular channel. In obtaining the dimensions of the equivalent coil the following considerations are to be noted. Although the method of winding varies somewhat in different cases, the wire is, in general, zigzagged across the surface of the cylinder on which the layer is being wound and returns to the boundary of the cross section from which it started only after making one complete turn plus the fractional part $\frac{\mathrm{r}}{2 n-1}$ th of another turn, where $n$ is a whole number. Thus $2 n$ complete turns bring the wire back to the starting point in the cross section but at the beginning of the third layer, and so on. Thus there will be $n$ turns per layer, and if $D$ be the distance between the centers of two adjacent turns in a layer, measured parallel to the axis of the coil, then $b=n D$. The distance between centers of turns in successive layers is equal to the diameter of the covered wires, so that $c=$ the number of layers times the diameter of the covered wire.

The correction for insulating space is larger for such coils than for those where the wires are wound side by side, but the expression for the correction must be more complicated, and on account of the difficulty of measuring the (usually) small dimensions of the coil with an accuracy which will warrant such a degree of precision in the calculated value of the inductance, it will hardly be worth while to attempt to take this correction into account. In such cases where it may seem difficult to follow the method of winding, fair accuracy in the inductance will be attained if the over-all dimensions of the coil be used.

EXAMPLE 4.-The dimensions of a honeycomb coil found by direct measurement, without any attempt being made to find the equivalent cross section, were as follows: Outside diameter, $31 / 4$ inches; depth of winding, $\frac{9}{16}$ inch; width of winding, $1 / 4$ inch; number of turns, 220. These give $a=\mathrm{I} \frac{11}{32}$ inches $=3.4 \mathrm{I} \mathrm{cm}, \frac{c}{2 a}=\frac{9}{43}=0.209$, 
$\frac{b}{c}=\frac{4}{9}$. Interpolating from Table $I$ the following values of $f$ were found, all for $\frac{b}{c}=\frac{4}{9}$,

\begin{tabular}{|c|c|c|c|}
\hline$\frac{c}{2 a}=$ & 0.2 & 0.3 & 0.4 \\
\hline$f=$ & 0.8536 & 0.8283 & 0.8053 \\
\hline
\end{tabular}

and interpolating between these for the above value of $\frac{c}{2 a}$, the value $f=0.85 \mathrm{I} 2$ is found. Table 3 gives for the value of $P$ corresponding to this same value of $\frac{c}{2 a}, 30.96$. Substituting in (4)

$$
L_{\mathrm{u}}=0.001(220)^{2} 3.41(30.96) 0.8512=4.35 \text { millihenries. }
$$

The observed value was 4.14 millihenries. As the dimensions of the equivalent coil always give a larger cross section than the overall dimensions, the calculated inductance would undoubtedly have been closer to the true value, if data had been available to allow of the calculation of the dimensions of the equivalent cross section.

\section{SOLENOIDS WOUND WITH STRIP OR LARGE ROUND WIRE}

The $b$ dimension of the equivalent coil in this case is to be taken as equal to the number of turns multiplied by the distance between centers of two adjacent conductors, and for the $c$ dimension the radial thickness of the strip. Having calculated the inductance of the equivalent coil, the correction for insulating space is to be evaluated just as in the case of the flat spiral below, with $c=w$, and $t=$ the thickness of the strip in the direction of the axis of the coil (see Example 5).

\section{FLAT SPIRALS}

Flat spiral coils are often used for radio coupling coils. They may be wound with metal ribbon, or with thicker strip of rectangular cross section, or with round wire. In each case the inductance calculated for the equivalent coil will generally be as close as I per cent to the truth without making the correction for insulating space.

If $n$ turns of wire of rectangular cross section are used whose width in the direction of the axis is $w$ (see Fig. 3 and Fig. 4), whose thickness is $t$ and whose pitch measured from the center of one 
turn to the center of the next is $D$, then the dimensions of the equivalent coil of rectangular cross section are to be taken as $b=w$, $c=n D$, and $a=a_{1}+\frac{\mathrm{I}}{2}(n-\mathrm{I}) D$, the distance $a_{1}$ being one-half of the distance $A B$, Figure 3 , measured from the innermost end of the spiral across the center of the spiral to the opposite point of the innermost turn. Having calculated $L_{\mathrm{u}}$ by (2) or (4), the correction for the insulating space is given by $\Delta L=0.01257 \mathrm{na}\left(A_{1}+B_{1}\right)$ in
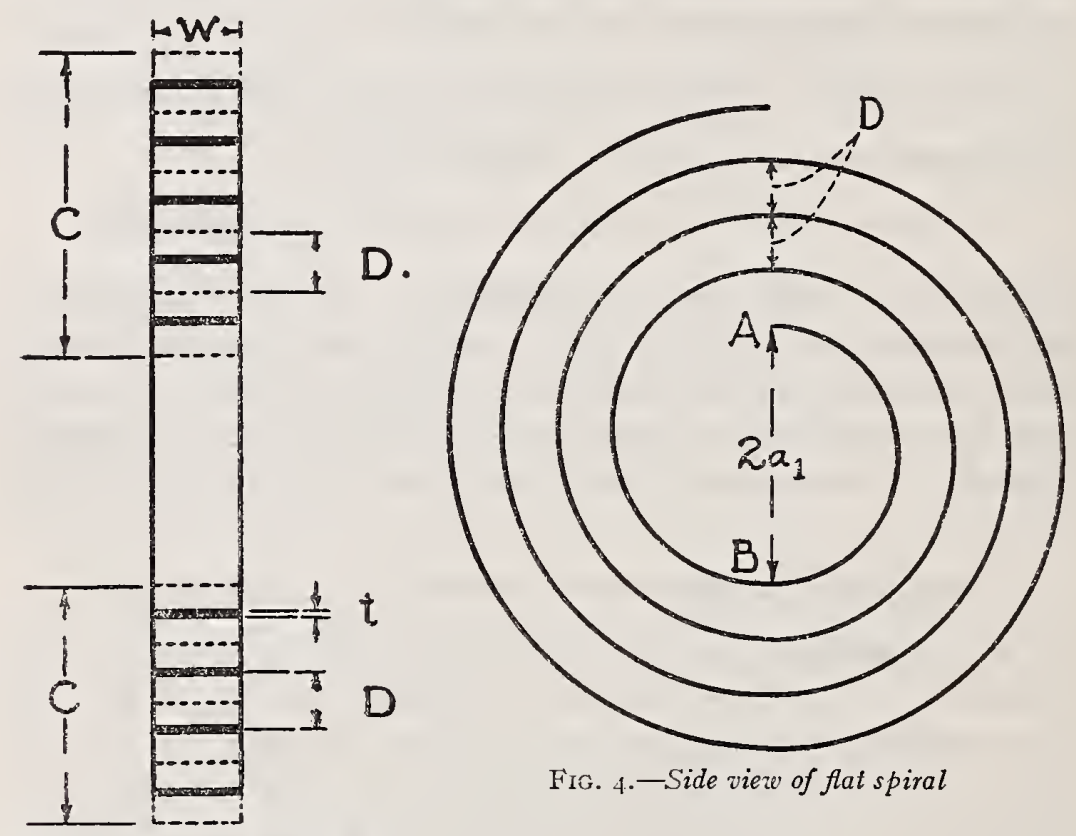

FIG. 3.-Sectional view of flal

spiral wound with metal ribbon

which the values of $A_{1}$ and $B_{1}$ depend on the cross section of the wire used. This correction is to be added to $L_{\mathrm{u}}$.

If we place $\frac{w}{D}=\nu$ and $\frac{t}{D}=\tau$, the equations for $A_{1}$ and $B_{1}$ are

$$
\left.\begin{array}{l}
A_{1}=\log _{\mathrm{e}} \frac{\nu+\mathrm{I}}{\nu+\tau}=2.303 \log _{10} \frac{\nu+\mathrm{I}}{\nu+\tau}, \\
B_{1}=-2\left[\frac{n-\mathrm{I}}{n} \delta_{12}+\frac{n-2}{n} \delta_{13}+\frac{n-3}{n} \delta_{14}+\ldots .+\frac{\mathrm{I}}{n} \delta_{1 \mathrm{n}}\right],
\end{array}\right\}
$$

in which $\delta_{12}, \delta_{13}$, etc., are given in Table 4 .

ExAmple 5.-For a spiral of 38 turns of copper ribbon whose cross sectional dimensions are $3 / 8$ by $\frac{1}{32}$ inch, the inner diameter was found to be $2 a_{1}=10.3 \mathrm{~cm}$ and the measured pitch $D=0.40 \mathrm{~cm}$ 
The dimensions of the equivalent coil of rectangular cross section are, accordingly, $b=\frac{3}{8}$ in. $=0.953 \mathrm{~cm}, a=\frac{10.3}{2}+\frac{\mathrm{I}}{2}(37)(0.4)=\mathrm{I} 2.55$ $\mathrm{cm}, c=38 \quad(0.40)=15.2 \mathrm{~cm}$. Thus $\frac{c}{2 a}=0.6056, \frac{b}{c}=0.0627$. By interpolation in Table $\mathrm{I}, f$ is found to be 0.9589 , and from Table 3 $P=18.52$. These values substituted in (4) give $L_{u}=321.8$ microhenries. For this spiral $\nu=2.38, \tau=0.198$ so that

$$
\begin{aligned}
& A_{1}=2.303 \log _{10} \frac{3.38}{2.58}=0.270, \\
& B_{1}=-2\left[\frac{37}{38}(0.028)+\frac{36}{38}(0.013)+\frac{35}{38}(0.007)+\frac{34}{38}(0.004)+\right. \\
& \left.\frac{33}{38}(0.003)+\frac{32}{38}(0.002)+\frac{31}{38}(0.002)+\frac{30}{38}(0.001)+\cdots\right]=-0.112, \\
& A_{1}+B_{1}=0.159,
\end{aligned}
$$

and the total correction is $0.01257(38)(12.55)(0.159)=0.95 \mathrm{mi}-$ crohenries. Adding this to $L_{\mathrm{u}}$ the total inductance is 322.8 microhenries. The measured value for this spiral was 323.5 microhenries.

If round wire is used for the spiral, the same method is followed for obtaining the mean radius $a$ and the dimension $c$, but is more convenient to calculate the inductance of the equivalent disk coil and thus set $b=0$. Thus in (4) $f=\mathrm{I}$, and $P^{\prime}=P$, which is to be taken from Table 3 . There must then be subtracted from this value of the inductance the correction $0.01257 n a(A+B)$ in which $A$ and $B$ are the same as apply to a solenoid of round wires and are given in Rosa's tables. ${ }^{33}$

7. CALCULATION OF MUTUAL INDUCTANCE OF COILS OF RECTANGULAR CROSS SECTION HAVING THE SAME LENGTH OR THE SAME MEAN RADIUS AND THICKNESS. APPLICATION TO THE CALCULATION OF THE LEAKAGE REACTANCE OF A TRANSFORMER

It is well known that the mutual inductance of two coils of rectangular cross section may in certain instances be obtained from the self-inductances of coils of rectangular cross section.

This is possible in the following cases:

I. Coaxial coils of equal mean radii and the same winding thickness $c$, the axial lengths and the distance between the coils being unrestricted.

${ }^{33}$ B. S. Sci. Papers, No. 169, Tables $\gamma$ and 8, p. 196-199. 
2. Concentric coaxial coils having the same axial dimension $b$, but with any desired thicknesses and, thus, unequal mean radii.

3. Coaxial coils of different mean radii and different winding thicknesses, but with equal axial lengths $b$, and so placed that the distance between their centers is some multiple of their axial length.

The first two of these cases are very simply treated by assuming a third coil 3 just filling the space between the coils $I$ and 2 .

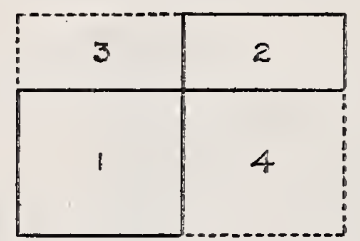

Axis

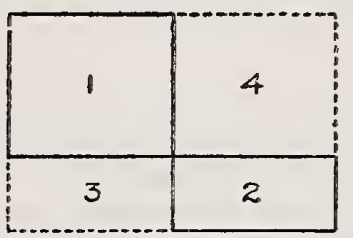

FIG. 5.-Equivalent coil system for calculation of mutual inductance of coaxial coils in contact (axial dimensions equal)

Supposing that all three coils were wound with a density of $N$ turns per $\mathrm{cm}^{2}$ of cross sectional area, the mutual inductance of coils I and 2 would be given by

$$
2 m_{12}=\left(L_{123}+L_{3}\right)-\left(L_{13}+L_{23}\right)
$$

in which $L_{123}$ is the self-inductance of the single coil composed of coils I, 2, and 3 , imagined to be joined in series with their fields in the same direction, $L_{13}$ is the inductance of the similar combination of coils I and 3 , etc. If $A_{1}, A_{2}$ represent the areas of cross section of coils I and 2, then $m_{12}$ corresponds to $N A_{1}$ turns on coil I and $N A_{2}$ on coil 2. But the coils have actually $n_{1}$ and $n_{2}$ turns, respectively, so that their true mutual inductance $M_{12}$ is greater than

$m_{12}$ in the ratio of $\left(\frac{n_{1}}{N A_{1}}\right)\left(\frac{n_{2}}{N A_{2}}\right)$. In this factor $\frac{n_{1}}{A_{1}}$ and $\frac{n_{2}}{A_{2}}$ are the actual winding densities, so that $M_{12}$ is obtained from $m_{12}$ by multiplying by the product of the ratios of the true winding densities to the assumed winding density $N$. The latter is, however, perfectly arbitrary, so that we may proceed most simply by assuming $N$ equal to unity. In this case the value of $m_{12}$ calculated by (7), under the assumption of a winding density of unity, needs only to be multiplied by the product of the actual winding densities of the coils.

If the coils are in contact, (7) becomes

$$
2 m_{12}=L_{12}-L_{1}-L_{2}
$$


For the third case, obliquely situated coils, the formulas are more complicated. Only that for the special case of coils in contact will be here given. Since the relations $L_{1}=L_{4}, L_{2}=L_{3}$, $M_{12}=M_{34}, L_{13}=L_{24}$, hold, this is

$$
{ }_{4} m_{12}=L_{1234}+2 L_{1}+2 L_{2}-2 L_{13}-L_{14}-L_{23} ;
$$

where the two fictitious coils 3 and 4 are shown in Figure 5. $M_{12}$ is obtained from $m_{12}$ as in the previous cases. It is to be noted that in all these mutual inductance formulas the calculated value is obtained as the difference of sums of positive and negative terms, each of which sums is larger than the desired quantity. Thus it is necessary to calculate the individual terms with a good deal of accuracy, in order to obtain an accurate value of the mutual inductance. This inconvenience is less important when the coils are in actual contact or very close together, and it is exactly these cases which are difficult to

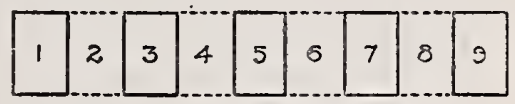
treat by other methods.

An interesting and important case where the self-inductance is readily obtained with accuracy from the principles involved in this section is that of the sectioned coil. By winding a number of equal coils in equally

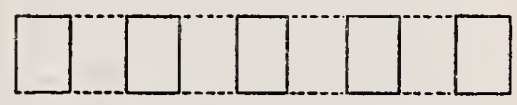

Fig. 6.-Equivalent coil system for calculation of inductance of sectioned coil spaced channels of rectangular cross section cut in a cylindrical form, and by joining these sections all in series, a coil of small capacity is obtained, but since the mutual inductances between the sections add to the self-inductances of the sections a total inductance of large value may be obtained.

Assuming fictitious coils which would just fill the spaces between the sections, and numbering these as shown in Figure 6, the inductance of a coil of $N$ sections is given by the formula

$$
\begin{aligned}
& L_{\mathrm{N}}=N L_{1}+(N-\mathrm{I})\left[L_{2}+L_{13}-2 L_{12}\right] \\
& +(N-2)\left[L_{24}+L_{15}-2 L_{14}\right] \\
& +(N-3)\left[L_{28}+L_{17}-2 L_{18}\right] \\
& +[N-(N-\mathrm{I})]\left[L_{2(2 \mathrm{~N}-2)}+\dot{\left.L_{1(2 \mathrm{~N}-1)}-2 \dot{L_{1(2 \mathrm{~N}-2)}}\right]} \dot{ }\right.
\end{aligned}
$$

in which $L_{1(2 \mathrm{~N}-1)}$ is the inductance of a coil consisting of all the sections and fictitious coils from section $\mathrm{I}$ to $(2 N-\mathrm{I})$, inclusive, etc. In a sectioned coil all the sections will usually be wound 


\section{$4 \longdiv { 2 }$}

with the same number of turns, so that we may assume the same winding density in the fictitious spacing coils as in the sections. If the sections differ among themselves, the principle already enunciated must be employed to obtain $M$ from $m$ and (Io) must be modified.

EXAMPLE 6.-The mutual inductance of two obliquely situated coils in contact was calculated by (9), the dimensions of the coils being

$$
\text { Coil I, } \begin{array}{rlrl}
a & =8 & \text { Coil } 2, a & =\text { I I } \\
b & =2 & b & =2 \\
c & =4 & c & =2
\end{array}
$$

\begin{tabular}{|c|c|c|c|c|c|c|}
\hline Item & $L_{124}$ & $L_{2}$ & $L_{2}$ & $L_{13}$ & $L_{11}$ & $L_{23}$ \\
\hline$b=$ & 4 & 2 & 2 & 2 & 4 & 4 \\
\hline$c=$ & 6 & 4 & 2 & 6 & 4 & 2 \\
\hline$a=$ & 9 & 8 & 11 & 9 & 8 & 11 \\
\hline $\bar{c}=$ & $1 / 3$ & $1 / 4$ & $1 / 11$ & $1 / 3$ & $1 / 4$ & $1 / 11$ \\
\hline$\frac{b}{c}=$ & $2 / 3$ & $1 / 2$ & 1 & $1 / 3$ & 1 & 2 \\
\hline$f=$ & c. 7536 & 0.8246 & 0.7892 & 0.8587 & 0.7057 & 0.6686 \\
\hline$P=$ & 25.298 & 28.767 & 41.298 & 25. 298 & 28.767 & 41.298 \\
\hline$P^{\prime}=$ & 19.065 & 23.721 & 32.593 & 21.723 & 20.300 & 27.512 \\
\hline$n^{2} a=$ & $9(24)^{2}$ & $8(8)^{2}$ & $11(16)$ & $9(144)$ & $8(16)^{2}$ & $11(8)^{2}$ \\
\hline Term $=l=$ & 98833 & 24290 & 11473 & 56306 & 41574 & 19439 \\
\hline
\end{tabular}

The following details are given to illustrate the method and the use of the tables. A winding density of unity is first assumed.

Dividing by 32 , the product of the areas of the cross sections, we find $4 M_{12}=539.90 n_{1} n_{2}$, or $M_{12}=0.13498 n_{1} n_{2}$ in microhenries the number of turns $n_{1}$ and $n_{2}$ unrestricted.

To check this result Lyle's formula (B. S. Sci. Paper $169,(28)$ ) is available, but for coils so close together it is necessary to subdivide the coils into a number of sections and to replace each section by two filaments. The mutual inductance in this present case was calculated with coil I divided into two sections, and then with coil 2 and the adjacent section of coil I each divided into two sections. Obtaining the mutual inductances of the various pairs of circular filaments by means of formula (I87) and Table I6, 
Circular 74 , a value of $M_{12}=0.13487 \quad n_{1} n_{2}$ microhenries was obtained.

EXAMPLE 7.-A coil is composed of four sections, which may be designated as I, 3, 5, and 7 in Figure 6, each having 400 turns, a mean radius $a=5 \mathrm{~cm}$, and cross sectional equivalent dimensions $b=c=2$, while the axial distance between the centers of adjacent segments is $4 \mathrm{~cm}$. Thus the fictitious spacing sections $2,4,6$ have the same dimensions as the actual sections of the coil.

From (ro), with $N=4$,

$$
L=4 L_{1}+3\left[L_{2}+L_{13}-2 L_{12}\right]+2\left[L_{24}+L_{15}-2 L_{14}\right]+\left[L_{26}+L_{17}-2 L_{16}\right]
$$

But for this case $L_{1}=L_{2}, L_{13}=L_{24}, L_{15}=L_{26}$, so that there results the special formula

$L=4 L_{1}+3\left[L_{1}+L_{13}-2 L_{12}\right]+2\left[L_{13}+L_{15}-2 L_{14}\right]+\left[L_{15}+L_{17}-2 L_{16}\right]$ (II)

The calculation then proceeds as follows:

$\left[a=5, \frac{c}{2 a}=0.2\right.$ in each case $]$

\begin{tabular}{|c|c|c|c|c|c|c|c|}
\hline Item & $L_{1}$ & $L_{12}$ & $L_{13}$ & $L_{14}$ & $L_{15}$ & $L_{15}$ & $L_{17}$ \\
\hline$b=$ & 2 & 4 & 6 & 8 & 10 & 12 & 14 \\
\hline$c=$ & 2 & 2 & 2 & 2 & 2 & 2 & 2 \\
\hline$\frac{c}{b}=$ & 1 & $1 / 2$ & $1 / 3$ & $1 / 4$ & $1 / 5$ & $1 / 6$ & $1 / 7$ \\
\hline$\frac{2 a}{b}=$ & 5 & $5 / 2$ & $5 / 3$ & $5 / 4$ & 1 & $5 / 6$ & $5 / 7$ \\
\hline$K=$ & & & 0.56969 & 0.63809 & & 0.72686 & 0.75709 \\
\hline$k=$ & & & .10750 & .11085 & & .11445 & .11536 \\
\hline$K^{\prime}=$ & 0.23258 & 0.37031 & .46219 & .52724 & 0.57530 & .61241 & .64173 \\
\hline
\end{tabular}

Since all the sections have the same density of winding, it is convenient to first make the calculation on the basis of a number of turns equal to the number of sections in the combination being considered. Multiplying by $0.002 \pi^{2}\left(\frac{2 a}{b}\right)$ times the square of this proportionate number of turns we find for the quantities in the brackets:

$$
\begin{aligned}
& L_{1}{ }^{\prime}=0.022955 \\
& L_{13}{ }^{\prime}=\text { o. } 136849 \\
& L_{15}{ }^{\prime}=0.283899 \\
& L_{13}{ }^{\prime}=.136849 \\
& L_{15}{ }^{\prime}=.283899 \\
& L_{17}{ }^{\prime}=.44335 \mathrm{I} \\
& \text { o. } 159804 \\
& \text { 0. } 420748 \\
& \text { o. } 72725^{\circ} \\
& -2 L_{12}{ }^{\prime}=-.146193 \\
& -2 L_{14}{ }^{\prime}=\frac{-.416292}{0.004456} \\
& -2 L_{16}{ }^{\prime}=-.725310 \\
& \text { o. } 0136 \mathrm{II} \\
& \text { o. } 001940
\end{aligned}
$$


so that (I I) gives

$$
\begin{array}{r}
4 \times 0.022955=0.091820 \\
3 \times 0.01361 \mathrm{I}=.040833 \\
2 \times 0.004456=.008912 \\
\mathrm{I} \times 0.001940=.001940 \\
\text { Sum }=0.143505
\end{array}
$$

Multiplying by the mean radius and the square of 400 , the actual number of turns per section, the inductance is I 4.80 millihenries. Using formula (3I), B. S. Sci. Papers, No. I69, to obtain the mutual inductances in the general formula

$$
L=4 L_{1}+6 M_{13}+4 M_{15}+2 M_{17},
$$

the result is

$$
\begin{aligned}
& \text { By (I 2) By (I I) } \\
& { }_{4} L_{1}=73.460=73.455 \text { millihenries } \\
& 6 M_{13}=32.55 \mathrm{I}=32.666 \\
& 4 M_{15}=7.278=7.130 \\
& 2 M_{17}=\mathrm{I} .55 \mathrm{I}=\mathrm{I} .55^{2} \\
& \text { II } 4.840 \quad \text { II } 4.803
\end{aligned}
$$

The formula (II) compared with (I2) shows that the terms in the brackets are equivalent to the mutual inductances $2 M_{13}, 2 M_{15}$, and $2 M_{17}$ in (I2). In order to make a comparison of the two methods, the values of these mutual inductances are given above also as derived from (I I) by multiplying each of the previously calculated values of the bracketed terms by $(400)^{2} a$.

Dr. E. J. Berg has suggested to me that the method of combination of self-inductances to obtain mutual inductances may also be applied to calculate the leakage reactance of transformer windings in such cases where disk or pancake coils are used. In such cases the presence of the iron core is of small effect on the leakage flux. (The usual method assumes coils of greater length.) The leakage reactance of each coil will be calculated as equal to $2 \pi f(L-M)$, where $L$ is the self-inductance of the winding calculated as in the absence of iron, and $M$ is the mutual inductance between the coil and an adjacent coil of the other winding, assuming the same density of winding in each. The leakage inductance of the whole winding is of course equal to the sum of the leakage inductances of the separate sections of the winding. The mutual inductances of the different sections of the same winding 
do not have to be considered in finding the leakage inductance. Both $L$ and $M$ can be found using formulas (2) or (4) and the tables. It is hoped to test the usefulness of this method in the near future.

The list of applications given here does not pretend to be exhaustive, but it is hoped that enough has been given to indicate the general method of procedure and to illustrate the use of the formulas and tables for general routine calculations of inductance.

\section{SUMMARY OF PRINCIPAL FORMULAS-INTERPOLATION FORMULA}

Let $L_{\mathrm{u}}=$ the inductance of the coil of rectangular cross section, assuming the current to be uniformly distributed over the cross section;

$a=$ the mean radius of the coil in centimeters;

$b=$ the dimension in centimeters of the cross section parallel to the axis of the coil;

$c=$ the radial dimension of the cross section in $\mathrm{cm}$;

$n=$ the number of turns in the coil;

then $L$ may be calculated by either of the following two formulas:

$$
\begin{aligned}
& L_{\mathrm{u}}=0.002 \pi^{2}\left(\frac{2 a}{b}\right) n^{2} a K^{\prime}=0.002 \pi^{2}\left(\frac{2 a}{b}\right) n^{2} a(K-k), \\
& L_{\mathrm{u}}=0.00 \mathrm{I} n^{2} a P^{\prime}=0.00 \mathrm{I} n^{2} a P f \text { microhenries, }
\end{aligned}
$$

in which the quantities $K^{\prime}, k, P^{\prime}$, and $f$ are given in Table I for the arguments $\frac{c}{2 a}$ and $\frac{b}{c}$ or $\frac{c}{b}$. Formula (2) is the better for long thin coils, while (4) is the better for pancake coils, although both may be used in any case and thus a check may be obtained.

When it is necessary to interpolate in the tables to obtain the value of $P^{\prime}$ or $K^{\prime}$, greater accuracy is obtained if the alternative forms of (2) and (4) are used. $k$ and $f$ may be interpolated from Table I with greater accuracy than can $P^{\prime}$ and $K^{\prime}$, while $K$ and $P$ can be obtained readily and with great accuracy from Tables 2 and 3 , respectively. In obtaining $k$ for very thin coils it is to be noted that for $\frac{c}{2 a}=0, k=0$ whatever the value of $\frac{c}{b}$. Excepting for thin pancake coils, interpolated values are somewhat more accurate for (2) than for (4). The latter has, however, the advantage of being the simpler formula and should give an accuracy of a part in a thousand even in unfavorable cases. 
In making interpolations in Tables $\mathbf{~}, 2$, and 3 second differences and in some cases third differences also need to be taken into account. This may readily be done by the use of the following interpolation formula and table of coefficients which are reproduced from B. S. Sci. Papers, No. 169, p. 213 and 214.

If tabulated values are given for the values $a$ and $(a+\delta)$ of the argument, their difference $f(a+\delta)-f(a)$ is the first difference. The difference of two consecutive first differences in the table is the second difference, etc. To obtain the value $f(a+h)$ corresponding to a value of the argument $(a+h)$ lying between $a$ and $(a+\delta)$, we have from Taylor's theorem

$$
\begin{aligned}
f(a+h) & =f(a)+H \Delta_{1}+\frac{H(H-I)}{2 !} \Delta_{2}+\frac{H(H-I)(H-2)}{3 !} \Delta_{3}+. \cdot . \\
& =f(a)+H_{1} \Delta_{1}+H_{2} \Delta_{2}+H_{3} \Delta_{3}+\ldots . .
\end{aligned}
$$

in which $H=\frac{h}{\delta}=$ the fraction of the tabulation interval for which interpolation is to be made, while $\Delta_{1}, \Delta_{2}$, etc., are, respectively, the first, second, and higher differences. The coefficients $H_{2}$ and $H_{3}$ may be taken at once from Table 5. Thus the process of interpolation is reduced to a simple operation, as the following example will show.

EXAMPLE 8.-To interpolate for the case $\frac{c}{2 a}=0.15, \frac{c}{b}=\mathrm{I}$. Taking from Table I the values of $k$ for $\frac{c}{b}=\mathrm{I}$ and different values

\begin{tabular}{|c|c|c|c|}
\hline$\frac{c}{2 a}$ & $k$ & $\Delta_{1}$ & $\Delta_{2}$ \\
\hline 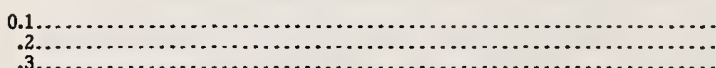 & $\begin{array}{r}0.04406 \\
.08725 \\
.12883\end{array}$ & $\begin{array}{r}+4319 \\
4158\end{array}$ & -161 \\
\hline
\end{tabular}
of $\frac{c}{2 a}$, we find the first and second differences as follows:

We have to interpolate for $h=0.15-0.10=0.05$ with a tabular interval of $\delta=0.2-0.1=0.1$. Thus $H_{1}=\frac{h}{\delta}=0.5$. Table 5 gives the value $H_{2}=-0.125$ corresponding to this value of $H_{1}$. Thus the interpolated value of $k$ is

$$
\begin{aligned}
& k=0.04406+\frac{\mathrm{I}}{2}(0.043 \mathrm{I} 9)-0 . \mathrm{I} 25(-0.00 \mathrm{I} 6 \mathrm{I}) \\
& k=0.04406+0.02 \mathrm{I} 60+0.00020=0.06586 .
\end{aligned}
$$

From Table 2 we have to take the value of $K$ for $\frac{2 a}{b}=\frac{20}{3}$ $=6.666 \ldots$ The following gives the scheme of interpolation: 


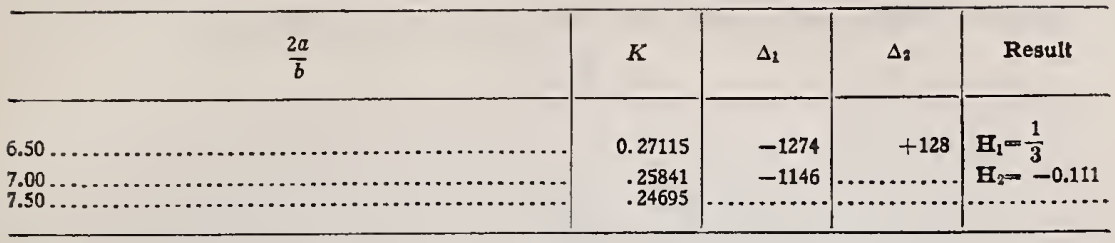

Thus $K=0.27$ I I $5-\frac{\text { I }}{3}$ 0.01274-0.I I I (0.00I28)

$$
K=0.27 \text { I I } 5-0.06586-0.000 I_{4}=0.26676,
$$

and thence $K^{\prime}=0.26676-0.06586=0.20090$.

In the case of $f$, the third difference has an appreciable effect-

\begin{tabular}{|c|c|c|c|c|c|}
\hline$\frac{c}{2 a}$ & $f$ & $\Delta_{1}$ & $\Delta_{2}$ & $\Delta_{3}$ & Result \\
\hline $\begin{array}{r}0.1 \\
2 \\
2 \\
.3 \ldots \\
.4 \ldots \ldots\end{array}$ & $\begin{array}{l}0.78373 \\
.72870 \\
.68483 \\
.64737\end{array}$ & $\begin{array}{l}-5503 \\
-4387 \\
-3746 \\
\ldots\end{array}$ & \begin{tabular}{r}
+1116 \\
641 \\
\hdashline$\ldots$. \\
\end{tabular} & 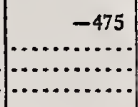 & $\begin{array}{l}\mathbf{H}_{1}=0.5 \\
\mathbf{H}_{2}-0.125 \\
\mathbf{H}_{3}=0.063 \\
\cdots \cdots \cdots\end{array}$ \\
\hline
\end{tabular}

$f=0.78373-0.0275^{2}-0.00140-0.00030=0.7545 \mathrm{I}$.

\section{THE TABLES}

TABLE 1.-Values of Constants $K^{\prime}, k, P^{\prime}$, and $f$ for Use in Formulas 2 and 4

$$
\frac{c}{2 a}=0.025
$$

\begin{tabular}{|c|c|c|c|c|c|c|c|c|c|c|c|}
\hline$\frac{b}{c}$ & $\boldsymbol{K}$ & $K^{\prime}$ & $k$ & $P^{\prime}$ & $f$ & $\frac{c}{b}$ & $K$ & $K^{\prime}$ & $k$ & $P^{\prime}$ & $f$ \\
\hline $\begin{array}{r}0 \\
0.1 \ldots \ldots \ldots \\
.2 \ldots \ldots \ldots \\
.3 \ldots \ldots \ldots \\
.4 \ldots \ldots \ldots \\
.5 \ldots \ldots \ldots\end{array}$ & $\begin{array}{c}0 \\
0.0109 \\
.0197 \\
.0276 \\
.0350 \\
.0419\end{array}$ & $\begin{array}{c}0 \\
0.0071 \\
.0140 \\
.0206 \\
.0270 \\
.0332\end{array}$ & $\begin{array}{c}0 \\
0.0038 \\
.0057 \\
.0070 \\
.0000 \\
.0088\end{array}$ & $\begin{array}{l}57.50 \\
56.27 \\
55.17 \\
54.17 \\
53.24 \\
52.38\end{array}$ & $\begin{array}{r}1.0000 \\
0.9787 \\
.9596 \\
.9421 \\
.9260 \\
.9110\end{array}$ & $\begin{array}{r}0.1 \ldots \ldots . \\
0.2 \ldots \ldots \\
.3 \ldots \ldots \\
.4 \ldots \ldots \\
.5 \ldots \ldots\end{array}$ & $\begin{array}{r}1.0000 \\
0.3654 \\
.2366 \\
.1790 \\
.1457 \\
.1236\end{array}$ & $\begin{array}{r}0.9835 \\
.3498 \\
.2219 \\
.1650 \\
.1322 \\
.1107\end{array}$ & $\begin{array}{l}0.0165 \\
.0156 \\
.0147 \\
.0140 \\
.0135 \\
.0129\end{array}$ & $\begin{array}{c}0 \\
27.62 \\
35.04 \\
39.08 \\
41.75 \\
43.68\end{array}$ & $\begin{array}{c}0 \\
0.4803 \\
.6094 \\
.6798 \\
.7262 \\
.7597\end{array}$ \\
\hline $\begin{array}{r}.6 \ldots \ldots \\
.7 \ldots \ldots \ldots \\
.8 \ldots \ldots \\
.9 \ldots \ldots \\
1.0 \ldots \ldots\end{array}$ & $\begin{array}{l}.0486 \\
.0549 \\
.0611 \\
.0670 \\
.0728\end{array}$ & $\begin{array}{l}.0392 \\
.0450 \\
.0508 \\
.0563 \\
.0618\end{array}$ & $\begin{array}{l}.0094 \\
.0099 \\
.0103 \\
.0107 \\
.0110\end{array}$ & $\begin{array}{l}51.57 \\
50.81 \\
50.09 \\
49.41 \\
48.77\end{array}$ & $\begin{array}{l}.8969 \\
.8837 \\
.8712 \\
.8594 \\
.8482\end{array}$ & $\begin{array}{r}.6 \ldots \ldots \\
.7 \ldots \ldots \\
.8 \ldots \ldots \\
1.0 \ldots \ldots\end{array}$ & $\begin{array}{l}.1078 \\
.0959 \\
.0866 \\
.0790 \\
.0728\end{array}$ & $\begin{array}{l}.0953 \\
.0838 \\
.0749 \\
.0677 \\
.0618\end{array}$ & $\begin{array}{l}.0125 \\
.0121 \\
.0117 \\
.0114 \\
.0110\end{array}$ & $\begin{array}{l}45.16 \\
46.33 \\
47.29 \\
48.09 \\
48.77\end{array}$ & $\begin{array}{l}.7854 \\
.8059 \\
.8225 \\
.8364 \\
.8482\end{array}$ \\
\hline
\end{tabular}

\begin{tabular}{|c|c|c|c|c|c|c|c|c|c|c|c|}
\hline 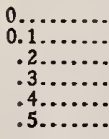 & $\begin{array}{c}0 \\
0.0197 \\
.0350 \\
.0486 \\
.0611 \\
.0728\end{array}$ & $\begin{array}{c}0 \\
0.0121 \\
.0235 \\
.0346 \\
.0451 \\
.0553\end{array}$ & $\begin{array}{c}0 \\
0.0076 \\
.0114 \\
.0140 \\
.0160 \\
.0175\end{array}$ & $\begin{array}{l}48.79 \\
47.57 \\
46.47 \\
45.47 \\
44.54 \\
43.68\end{array}$ & $\begin{array}{r}1.0000 \\
0.9749 \\
.9524 \\
.9318 \\
.9128 \\
.8951\end{array}$ & $\begin{array}{r}0 \ldots \ldots \\
0.1 \ldots \\
.2 \ldots \\
.3 \ldots \\
.4 \ldots \\
.5 \ldots\end{array}$ & $\begin{array}{r}1.0000 \\
0.5255 \\
.3654 \\
.2854 \\
.2366 \\
.2033\end{array}$ & $\begin{array}{r}0.9675 \\
.4947 \\
.3361 \\
.2574 \\
.2097 \\
.1774\end{array}$ & $\begin{array}{r}0.0325 \\
.0308 \\
.0293 \\
.0280 \\
.0269 \\
.0259\end{array}$ & $\begin{array}{l}0 \\
19.53 \\
26.54 \\
30.48 \\
33.11 \\
35.02\end{array}$ & $\begin{array}{c}0 \\
0.4002 \\
.5439 \\
.6247 \\
.6786 \\
.7178\end{array}$ \\
\hline & $\begin{array}{l}.0839 \\
.0945 \\
.1046 \\
.1143 \\
.1236\end{array}$ & $\begin{array}{l}.0651 \\
.0747 \\
.0839 \\
.0928 \\
.1015\end{array}$ & $\begin{array}{l}.0188 \\
.0198 \\
.0207 \\
.0215 \\
.0221\end{array}$ & $\begin{array}{l}42.87 \\
42.11 \\
41.40 \\
40.72 \\
40.08\end{array}$ & $\begin{array}{l}.8786 \\
.8630 \\
.8484 \\
.8345 \\
.8214\end{array}$ & $\begin{array}{r}.6 . \\
.7 . \\
.8 \\
.9 \\
1.0\end{array}$ & $\begin{array}{r}.1790 \\
.1604 \\
.1457 \\
.1336 \\
.1236\end{array}$ & $\begin{array}{r}.1540 \\
.1362 \\
.1222 \\
.1109 \\
.1015\end{array}$ & $\begin{array}{l}.0250 \\
.0242 \\
.0234 \\
.0227 \\
.0221\end{array}$ & & $\begin{array}{l}.7478 \\
.7717 \\
.7912 \\
.8075 \\
.8214\end{array}$ \\
\hline
\end{tabular}

$$
\frac{c}{2 a}=0.05
$$


TABLE 1.-Values of Constants $K^{\prime}, k, P^{\prime}$, and for Use in Formulas 2 and $4-C o n$.

\begin{tabular}{|c|c|c|c|c|c|c|c|c|c|c|c|}
\hline$\frac{b}{c}$ & $K$ & $K^{\prime}$ & $k$ & $P^{\prime}$ & $f$ & $\frac{c}{b}$ & $K$ & $K^{\prime}$ & $k$ & $p^{\prime}$ & $f$ \\
\hline $\begin{array}{r}0 \ldots \ldots \\
0.1 \\
.2 \ldots \ldots \\
.3 \ldots \ldots \\
.4 \ldots \ldots \\
.5 \ldots \ldots\end{array}$ & $\begin{array}{c}0 \\
0.0350 \\
.0611 \\
.0839 \\
.1046 \\
.1236\end{array}$ & $\begin{array}{l}0 \\
0.0197 \\
.0383 \\
.0559 \\
.0727 \\
.0887\end{array}$ & $\begin{array}{c}0 \\
0.0153 \\
.0228 \\
.0280 \\
.0319 \\
.0349\end{array}$ & $\begin{array}{l}40.11 \\
38.89 \\
37.79 \\
36.79 \\
35.86 \\
35.00\end{array}$ & $\begin{array}{r}1.0000 \\
0.9695 \\
.9422 \\
.9172 \\
.8941 \\
.8727\end{array}$ & $\begin{array}{r}0 . \ldots \\
0.1 \ldots \\
.2 \ldots \\
.3 \ldots \\
.4 \ldots \\
.5 \ldots\end{array}$ & $\begin{array}{r}1.0000 \\
0.6884 \\
.5255 \\
.4292 \\
.3654 \\
.3198\end{array}$ & $\begin{array}{r}0.9367 \\
.6276 \\
.4674 \\
.3735 \\
.3119 \\
.2682\end{array}$ & $\begin{array}{r}0.063^{2} \\
.0608 \\
.0581 \\
.0557 \\
.0535 \\
.0516\end{array}$ & $\begin{array}{c}0 \\
12.39 \\
18.45 \\
22.12 \\
24.63 \\
26.48\end{array}$ & $\begin{array}{l}0 \\
0.3088 \\
.4600 \\
.5514 \\
.6140 \\
.6600\end{array}$ \\
\hline $\begin{array}{r}.6 \ldots \ldots \ldots \\
.7 \ldots \ldots \\
.8 \ldots \ldots \\
.9 \ldots \ldots \\
1.0 \ldots \ldots\end{array}$ & $\begin{array}{l}.1414 \\
.1581 \\
.1739 \\
.1890 \\
.2033\end{array}$ & $\begin{array}{l}.1040 \\
.1186 \\
.1327 \\
.1462 \\
.1593\end{array}$ & $\begin{array}{l}.0374 \\
.0395 \\
.0413 \\
.0428 \\
.0441\end{array}$ & $\begin{array}{l}34.20 \\
33.45 \\
32.74 \\
32.07 \\
31.44\end{array}$ & $\begin{array}{l}.8527 \\
.8339 \\
.8162 \\
.7995 \\
.7837\end{array}$ & $\begin{array}{r}.6 \ldots \\
.7 \ldots \\
.8 \ldots \\
.9 \ldots \\
1.0 \ldots\end{array}$ & $\begin{array}{l}.2854 \\
.2584 \\
.2366 \\
.2185 \\
.2033\end{array}$ & $\begin{array}{l}.2356 \\
.2102 \\
.1899 \\
.1732 \\
.1593\end{array}$ & $\begin{array}{l}.0498 \\
.0482 \\
.0467 \\
.0453 \\
.0441\end{array}$ & $\begin{array}{l}27.90 \\
29.05 \\
29.98 \\
30.77 \\
31.44\end{array}$ & $\begin{array}{l}.6957 \\
.7242 \\
.7475 \\
.7671 \\
.7837\end{array}$ \\
\hline
\end{tabular}

$$
\frac{c}{2 a}=0.2
$$

\begin{tabular}{|c|c|c|c|c|c|c|c|c|c|c|c|}
\hline $\begin{array}{l}0.1 \ldots \\
.2 . \\
.3 . \\
.4 . \\
.5 .\end{array}$ & $\begin{array}{c}0 \\
0.0611 \\
.1046 \\
.1414 \\
.1739 \\
.2033\end{array}$ & $\begin{array}{c}0 \\
0.0307 \\
.0592 \\
.0857 \\
.1106 \\
.1339\end{array}$ & $\begin{array}{c}0 \\
0.0304 \\
.0454 \\
.0557 \\
.0634 \\
.0694\end{array}$ & $\begin{array}{l}31.50 \\
30.28 \\
29.19 \\
28.19 \\
27.28 \\
26.43\end{array}$ & $\begin{array}{r}1.0000 \\
0.9612 \\
.9266 \\
.8950 \\
.8660 \\
.8391\end{array}$ & $\begin{array}{r}0 \ldots \ldots \\
0.1 \ldots \\
.2 \ldots \\
.3 \ldots \\
.4 \ldots \\
.5 \ldots\end{array}$ & $\begin{array}{r}1.0000 \\
0.8181 \\
.6884 \\
.5950 \\
.5255 \\
.4719\end{array}$ & $\begin{array}{r}0.8800 \\
.7012 \\
.5753 \\
.4863 \\
.4204 \\
.3703\end{array}$ & $\begin{array}{r}0.1200 \\
.1170 \\
.1131 \\
.1088 \\
.1051 \\
.1016\end{array}$ & $\begin{array}{l}0 \\
6.92 \\
11.36 \\
14.40 \\
16.60 \\
18.27\end{array}$ & $\begin{array}{r}0 \\
0.2197 \\
.3608 \\
.4571 \\
.5269 \\
.5801\end{array}$ \\
\hline $\begin{array}{r}8 . \\
9.9 \\
1.0\end{array}$ & $\begin{array}{r}.2302 \\
.2550 \\
.2781 \\
.2396 \\
.3198\end{array}$ & $\begin{array}{r}.1559 \\
.1766 \\
.1963 \\
.2149 \\
.2326\end{array}$ & $\begin{array}{l}.0743 \\
.0784 \\
.0818 \\
.0847 \\
.0872\end{array}$ & $\begin{array}{l}25.64 \\
24.91 \\
24.22 \\
23.57 \\
22.95\end{array}$ & $\begin{array}{l}.8141 \\
.7907 \\
.7688 \\
.7482 \\
.7287\end{array}$ & $\begin{array}{r}.6 . \\
.7 . \\
.8 . \\
.9 . \\
1.0 .\end{array}$ & $\begin{array}{l}.4292 \\
.3944 \\
.3654 \\
.3409 \\
.3198\end{array}$ & $\begin{array}{r}.3310 \\
.2992 \\
.2731 \\
.2512 \\
.2326\end{array}$ & $\begin{array}{r}0982 \\
.0952 \\
.0923 \\
.0897 \\
.0872\end{array}$ & $\begin{array}{l}19.60 \\
20.67 \\
21.56 \\
22.31 \\
22.95\end{array}$ & $\begin{array}{l}.6222 \\
.6563 \\
.6845 \\
.7083 \\
.7287\end{array}$ \\
\hline
\end{tabular}

$$
\frac{c}{2 a}=0.3
$$

\begin{tabular}{|c|c|c|c|c|c|c|c|c|c|c|c|}
\hline $\begin{array}{r}0.1 \ldots \\
0.1 \ldots \ldots \\
.2 \ldots \\
.3 \ldots \\
.4 \ldots \\
.5 \ldots\end{array}$ & $\begin{array}{c}0 \\
0.0839 \\
.1414 \\
.1890 \\
.2302 \\
.2667\end{array}$ & $\begin{array}{c}0 \\
0.0386 \\
.0737 \\
.1061 \\
.1360 \\
.1637\end{array}$ & $\begin{array}{c}0 \\
0.0453 \\
.0677 \\
.0829 \\
.0942 \\
.1030\end{array}$ & $\begin{array}{l}26.56 \\
25.34 \\
24.26 \\
23.27 \\
22.37 \\
21.54\end{array}$ & $\begin{array}{l}1.0000 \\
0.9541 \\
.9133 \\
.8762 \\
.8423 \\
.8111\end{array}$ & $\begin{array}{r}0 . \ldots \ldots \ldots \\
0.1 \ldots \ldots \ldots \\
.2 \ldots \ldots \ldots \\
.3 \ldots \ldots \\
.4 \ldots \ldots \\
.5 \ldots \ldots\end{array}$ & $\begin{array}{l}1.0000 \\
0.8722 \\
.7699 \\
.6884 \\
.6230 \\
.5697\end{array}$ & $\begin{array}{l}0.8300 \\
.7051 \\
.6069 \\
.5301 \\
.4697 \\
.4210\end{array}$ & $\begin{array}{l}0.1700 \\
.1671 \\
.1630 \\
.1533 \\
.1533 \\
.1487\end{array}$ & $\begin{array}{c}0 \\
4.64 \\
7.99 \\
10.46 \\
12.36 \\
13.85\end{array}$ & $\begin{array}{c}0 \\
0.1747 \\
.3007 \\
.3940 \\
.4654 \\
.5215\end{array}$ \\
\hline & $\begin{array}{l}.2996 \\
.3295 \\
.3568 \\
.3820 \\
.4053\end{array}$ & $\begin{array}{l}.1894 \\
.2134 \\
.2358 \\
.2568 \\
.2764\end{array}$ & $\begin{array}{l}.1102 \\
.1160 \\
.1210 \\
.1252 \\
.1288\end{array}$ & $\begin{array}{l}20.77 \\
20.06 \\
19.40 \\
18.77 \\
18.19\end{array}$ & $\begin{array}{l}.7822 \\
.7554 \\
.7303 \\
.7068 \\
.6848\end{array}$ & $\begin{array}{l}.6 . \\
.7 . \\
.8 . \\
.9 . \\
1.0 .\end{array}$ & $\begin{array}{l}.5255 \\
.4883 \\
.4566 \\
.4292 \\
.4053\end{array}$ & $\begin{array}{l}.3813 \\
.3483 \\
.3206 \\
.2969 \\
.2764\end{array}$ & $\begin{array}{l}.1442 \\
.1400 \\
.1360 \\
.1323 \\
.1288\end{array}$ & $\begin{array}{l}15.05 \\
16.04 \\
16.87 \\
17.58 \\
18.19\end{array}$ & $\begin{array}{l}.5668 \\
.6041 \\
.6353 \\
.6619 \\
.6848\end{array}$ \\
\hline
\end{tabular}

\begin{tabular}{|c|c|c|c|c|c|c|c|c|c|c|c|}
\hline 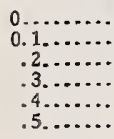 & $\begin{array}{c}0 \\
0.1046 \\
.1739 \\
.2302 \\
.2781 \\
.3198\end{array}$ & $\begin{array}{c}0 \\
0.0445 \\
.0845 \\
.1209 \\
.1541 \\
.1844\end{array}$ & $\begin{array}{c}0 \\
0.0601 \\
.0894 \\
.1093 \\
.1240 \\
.1354\end{array}$ & $\begin{array}{l}23.15 \\
21.93 \\
20.86 \\
19.89 \\
19.01 \\
18.20\end{array}$ & $\begin{array}{r}1.0000 \\
0.9474 \\
.9010 \\
.8591 \\
.8210 \\
.7861\end{array}$ & $\begin{array}{r}0 . \ldots \ldots \ldots \\
0.1 \ldots \ldots \\
.2 \ldots \ldots \\
.3 \ldots \ldots \\
.4 \ldots \ldots \\
.5 \ldots \ldots \\
\end{array}$ & $\begin{array}{r}1.0000 \\
0.9016 \\
.8181 \\
.7478 \\
.6884 \\
.6381\end{array}$ & $\begin{array}{l}0.7867 \\
.6907 \\
.6110 \\
.5453 \\
.4912 \\
.4465\end{array}$ & $\begin{array}{r}0.2133 \\
.2109 \\
.2071 \\
.2024 \\
.1973 \\
.1916\end{array}$ & $\begin{array}{c}0 \\
3.41 \\
6.03 \\
8.07 \\
9.70 \\
11.02\end{array}$ & $\begin{array}{c}0 \\
0.1472 \\
.2604 \\
.3487 \\
.4188 \\
.4759\end{array}$ \\
\hline $\begin{array}{r}.6 \ldots \ldots \ldots \\
.7 \ldots \ldots \ldots \\
.8 \ldots \ldots \ldots \\
1.0 \ldots \ldots\end{array}$ & $\begin{array}{l}.3568 \\
.3900 \\
.4199 \\
.4470 \\
.4719\end{array}$ & $\begin{array}{l}.2122 \\
.2379 \\
.2615 \\
.2834 \\
.3036\end{array}$ & $\begin{array}{l}.1446 \\
.1521 \\
.1584 \\
.1637 \\
.1683\end{array}$ & $\begin{array}{l}17.45 \\
16.77 \\
16.13 \\
15.54 \\
14.99\end{array}$ & $\begin{array}{l}.7540 \\
.7243 \\
.6968 \\
.6712 \\
.6474\end{array}$ & $\begin{array}{l}.6 . . \\
.7 . . \\
.8 . \\
.9 . . \\
1.0 . .\end{array}$ & $\begin{array}{l}.5950 \\
.5579 \\
.5255 \\
.4971 \\
.4719\end{array}$ & $\begin{array}{l}.4084 \\
.3761 \\
.3485 \\
.3246 \\
.3036\end{array}$ & $\begin{array}{l}.1866 \\
.1818 \\
.1770 \\
.1725 \\
.1683\end{array}$ & $\begin{array}{l}12.09 \\
12.99 \\
13.76 \\
14.42 \\
14.99\end{array}$ & $\begin{array}{l}.5224 \\
.5612 \\
.5944 \\
.6227 \\
.6474\end{array}$ \\
\hline
\end{tabular}

$$
\frac{c}{2 a}=0.4
$$

\begin{tabular}{|c|c|c|c|c|c|c|c|c|c|c|c|}
\hline \multicolumn{12}{|c|}{$\frac{c}{2 a}=0.5$} \\
\hline $\begin{array}{r}0 \\
0.1 \ldots \ldots \\
.2 \ldots \ldots \\
.3 \ldots \ldots \\
.4 \ldots \ldots \\
.5 \ldots \ldots \\
\end{array}$ & $\begin{array}{c}0 \\
0.1236 \\
.2033 \\
.2667 \\
.3198 \\
.3654\end{array}$ & $\begin{array}{c}0 \\
0.0491 \\
.0928 \\
.1320 \\
.1673 \\
.1991\end{array}$ & $\begin{array}{c}0 \\
0.0745 \\
.1105 \\
.1347 \\
.1526 \\
.1663\end{array}$ & $\begin{array}{l}20.60 \\
19.39 \\
18.32 \\
17.37 \\
16.51 \\
15.72\end{array}$ & $\begin{array}{l}1.0000 \\
0.9412 \\
.8894 \\
.8431 \\
.8013 \\
.7632\end{array}$ & $\begin{array}{l}0 . . \\
0.1 . \\
.2 . \\
.3 . \\
.4 . \\
.5 .\end{array}$ & $\begin{array}{l}1.0000 \\
0.9201 \\
.8498 \\
.7885 \\
.7351 \\
.6884\end{array}$ & $\begin{array}{r}0.7500 \\
.6717 \\
.6045 \\
.5475 \\
.4990 \\
.4576\end{array}$ & $\begin{array}{r}0.2500 \\
.2484 \\
.2453 \\
.2410 \\
.2361 \\
.2308\end{array}$ & $\begin{array}{c}0 \\
2.65 \\
4.77 \\
6.48 \\
7.88 \\
9.03\end{array}$ & $\begin{array}{l}0 \\
0.1287 \\
.2317 \\
.3147 \\
.3825 \\
.4385\end{array}$ \\
\hline $\begin{array}{r}.6 \ldots \ldots \\
.7 \ldots \ldots \\
.8 \ldots \ldots \\
1.9 \ldots \ldots \\
1.0 \ldots \ldots\end{array}$ & $\begin{array}{l}.4053 \\
.4405 \\
.4719 \\
.5000 \\
.5255\end{array}$ & $\begin{array}{l}.2281 \\
.2544 \\
.2785 \\
.3005 \\
.3208\end{array}$ & $\begin{array}{l}.1772 \\
.1861 \\
.1934 \\
.1995 \\
.2047\end{array}$ & $\begin{array}{l}15.01 \\
14.35 \\
13.74 \\
13.18 \\
12.66\end{array}$ & $\begin{array}{l}.7284 \\
.6965 \\
.6672 \\
.6399 \\
.6148\end{array}$ & $\begin{array}{l}.6 . . \\
.7 . . \\
.8 . . \\
.9 . \\
1.0 .\end{array}$ & $\begin{array}{l}.6475 \\
.6115 \\
.5795 \\
.5511 \\
.5255\end{array}$ & $\begin{array}{l}.4223 \\
.3916 \\
.3649 \\
.3415 \\
.3208\end{array}$ & $\begin{array}{l}.2252 \\
.2199 \\
.2147 \\
.2096 \\
.2047\end{array}$ & $\begin{array}{l}10.00 \\
10.82 \\
11.52 \\
12.13 \\
12.66\end{array}$ & $\begin{array}{l}.4856 \\
.5533 \\
.5594 \\
.5890 \\
.6148\end{array}$ \\
\hline
\end{tabular}


T.1BLE 1.-Values of Constants $K^{\prime}, k, P^{\prime}$, and $f$ for Use in Formulas 2 and $4-C o n$.

\begin{tabular}{|c|c|c|c|c|c|c|c|c|c|c|c|}
\hline$\frac{b}{c}$ & $K$ & $K^{\prime}$ & $k$ & $P^{\prime}$ & $f$ & $\frac{c}{b}$ & $K$ & $K^{\prime}$ & $\boldsymbol{k}$ & $P^{\prime}$ & $f$ \\
\hline $\begin{array}{r}0 \\
0.1 \ldots \ldots \\
.2 \ldots \ldots \\
.3 \ldots \ldots \\
.4 \ldots \ldots \\
.5 \ldots \ldots\end{array}$ & $\begin{array}{c}0 \\
0.1414 \\
.2302 \\
.2996 \\
.3568 \\
.4053\end{array}$ & $\begin{array}{c}0 \\
0.0529 \\
.0994 \\
.1406 \\
.1772 \\
.2100\end{array}$ & $\begin{array}{c}0 \\
0.0885 \\
.1308 \\
.1590 \\
.1796 \\
.1953\end{array}$ & $\begin{array}{l}18.61 \\
17.41 \\
16.35 \\
15.42 \\
14.58 \\
13.82\end{array}$ & $\begin{array}{l}1.0000 \\
0.9351 \\
.8785 \\
.8282 \\
.7831 \\
.7424\end{array}$ & $\begin{array}{r}0 \\
0.1 \ldots \ldots \ldots \\
.2 \ldots \ldots \\
.3 \ldots \ldots . \\
.4 \ldots \ldots \\
.5 \ldots \ldots\end{array}$ & $\begin{array}{r}1.0000 \\
0.9327 \\
.8722 \\
.8181 \\
.7699 \\
.7269\end{array}$ & $\begin{array}{r}0.7200 \\
.6533 \\
.5949 \\
.5443 \\
.5004 \\
.4624\end{array}$ & $\begin{array}{r}0.2800 \\
.2795 \\
.2773 \\
.2739 \\
.2695 \\
.2645\end{array}$ & $\begin{array}{l}0 \\
2.15 \\
3.91 \\
5.37 \\
6.58 \\
7.61\end{array}$ & $\begin{array}{c}0 \\
0.1155 \\
.2103 \\
.2886 \\
.3537 \\
.4086\end{array}$ \\
\hline $\begin{array}{r}.6 \ldots \ldots \ldots \\
.7 \ldots \ldots \ldots \\
.8 . \ldots \ldots \\
1.0 \ldots \ldots \ldots\end{array}$ & $\begin{array}{l}.4470 \\
.4835 \\
.5156 \\
.5542 \\
.5697\end{array}$ & $\begin{array}{l}.2394 \\
.2660 \\
.2901 \\
.3119 \\
.3319\end{array}$ & $\begin{array}{l}.2076 \\
.2175 \\
.2255 \\
.2323 \\
.2378\end{array}$ & $\begin{array}{l}13.13 \\
12.50 \\
11.93 \\
11.40 \\
10.92\end{array}$ & $\begin{array}{l}.7054 \\
.6717 \\
.6409 \\
.6124 \\
.5865\end{array}$ & $\begin{array}{r}.6 \ldots \ldots . \\
.7 \ldots \ldots \\
.8 \ldots \ldots \\
.9 \ldots \ldots \\
1.0 \ldots \ldots\end{array}$ & $\begin{array}{l}.6884 \\
.6540 \\
.6230 \\
.5950 \\
.5697\end{array}$ & $\begin{array}{l}.4293 \\
.4003 \\
.3747 \\
.3520 \\
.3319\end{array}$ & $\begin{array}{l}.2592 \\
.2536 \\
.2483 \\
.2430 \\
.2378\end{array}$ & $\begin{array}{r}8.47 \\
9.22 \\
9.86 \\
10.42 \\
10.92\end{array}$ & $\begin{array}{l}.4552 \\
.4953 \\
.5298 \\
.5600 \\
.5865\end{array}$ \\
\hline
\end{tabular}

\begin{tabular}{|c|c|c|c|c|c|c|c|c|c|c|c|}
\hline \multicolumn{12}{|c|}{$\frac{c}{2 a}=0.7$} \\
\hline $\begin{array}{r}0, \ldots \ldots \ldots \\
0.1 \ldots \ldots \ldots \\
.2 \ldots \ldots \\
.3 \ldots \ldots \ldots \\
.4 \ldots \ldots \\
.5 \ldots \ldots \\
\end{array}$ & $\begin{array}{l}0 \\
0.1581 \\
.2550 \\
.3295 \\
.3899 \\
.4405\end{array}$ & $\begin{array}{l}0 \\
0.0561 . \\
.1049 \\
.1476 \\
.1851 \\
.2185\end{array}$ & $\begin{array}{l}0 \\
0.1020 \\
.1501 \\
.1819 \\
.2048 \\
.2220\end{array}$ & $\begin{array}{l}17.03 \\
15.83 \\
14.79 \\
13.87 \\
13.05 \\
12.32\end{array}$ & $\begin{array}{r}1.0000 \\
0.9293 \\
.8683 \\
.8143 \\
.7664 \\
.7234\end{array}$ & $\begin{array}{r}0.1 \ldots \ldots \\
.2 \ldots \ldots \\
.3 \ldots \ldots \\
.4 \ldots \ldots \\
.5 \ldots \ldots\end{array}$ & $\begin{array}{r}1.0000 \\
0.9419 \\
.8888 \\
.8406 \\
.7968 \\
.7571\end{array}$ & $\begin{array}{l}0.6967 \\
.6379 \\
.5858 \\
.5399 \\
.4996 \\
.4642\end{array}$ & $\begin{array}{l}0.3033 \\
.3040 \\
.3031 \\
.3007 \\
.2972 \\
.2929\end{array}$ & $\begin{array}{l}0 \\
1.80 \\
3.30 \\
4.57 \\
5.64 \\
6.54\end{array}$ & $\begin{array}{l}0 \\
0.1056 \\
.1940 \\
.2682 \\
.3309 \\
.3843\end{array}$ \\
\hline $\begin{array}{r}.6 \ldots \ldots \\
.7 \ldots \ldots \\
.8 \ldots \ldots \\
1.9 \ldots \ldots\end{array}$ & $\begin{array}{l}.4835 \\
.5206 \\
.5530 \\
.5815 \\
.6067\end{array}$ & $\begin{array}{l}.2481 \\
.2747 \\
.2986 \\
.3201 \\
.3395\end{array}$ & $\begin{array}{l}.2354 \\
.2459 \\
.2544 \\
.2614 \\
.2672\end{array}$ & $\begin{array}{r}11.66 \\
11.07 \\
10.52 \\
10.03 \\
9.58\end{array}$ & $\begin{array}{l}.6847 \\
.6497 \\
.6179 \\
.5888 \\
.5621\end{array}$ & $\begin{array}{r}.6 \ldots \ldots \\
.7 \ldots \ldots \\
.8 \ldots \ldots \\
.9 \ldots \ldots\end{array}$ & $\begin{array}{l}.7211 \\
.6884 \\
.6587 \\
.6315 \\
.6067\end{array}$ & $\begin{array}{l}.4330 \\
.4054 \\
.3809 \\
.3591 \\
.3395\end{array}$ & $\begin{array}{l}.2881 \\
.2830 \\
.2777 \\
.2724 \\
.2672\end{array}$ & $\begin{array}{l}7.33 \\
8.00 \\
8.59 \\
9.11 \\
9.58\end{array}$ & $\begin{array}{l}.4302 \\
.4699 \\
.5046 \\
.5351 \\
.5621\end{array}$ \\
\hline
\end{tabular}

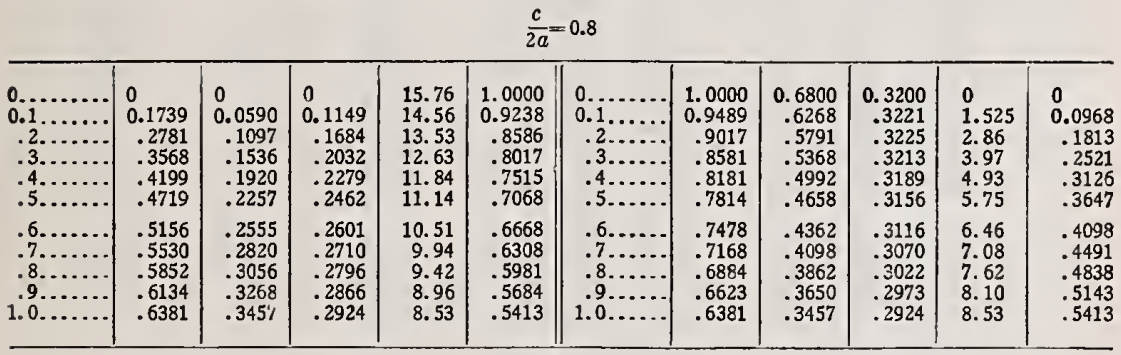

\begin{tabular}{|c|c|c|c|c|c|c|c|c|c|c|c|}
\hline \multicolumn{12}{|c|}{$\frac{c}{2 a}=0.9$} \\
\hline $\begin{array}{r}0 \\
0.1 \ldots \ldots \\
.2 \ldots \ldots \\
.3 \ldots \ldots \\
.4 \ldots \ldots \\
.5 \ldots \ldots \\
\end{array}$ & $\begin{array}{l}0 \\
0.1890 \\
.2996 \\
.3820 \\
.4470 \\
.5000\end{array}$ & $\begin{array}{l}0 \\
0.0617 \\
.1142 \\
.1594 \\
.1986 \\
.2328\end{array}$ & $\begin{array}{l}0 \\
0.1272 \\
.1854 \\
.2226 \\
.2484 \\
.2672\end{array}$ & $\begin{array}{l}14.74 \\
13.54 \\
12.53 \\
11.65 \\
10.88 \\
10.21\end{array}$ & $\begin{array}{l}1.0000 \\
0.9187 \\
.8497 \\
.7905 \\
.7388 \\
.6929\end{array}$ & $\begin{array}{r}0 \\
0.1 \\
.2 \ldots \ldots \\
.3 \ldots \ldots \\
.4 \ldots \ldots \\
.5 \ldots \ldots \\
\end{array}$ & $\begin{array}{r}1.0000 \\
0.9544 \\
.9118 \\
.8722 \\
.8355 \\
.8014\end{array}$ & $\begin{array}{r}0.6700 \\
.6207 \\
.5762 \\
.5364 \\
.5007 \\
.4689\end{array}$ & $\begin{array}{l}0.3300 \\
.3337 \\
.3356 \\
.3359 \\
.3347 \\
.3326\end{array}$ & $\begin{array}{l}0 \\
1.36 \\
2.53 \\
3.53 \\
4.39 \\
5.14\end{array}$ & $\begin{array}{l}0 \\
0.0924 \\
.1715 \\
.2394 \\
.2980 \\
.3488\end{array}$ \\
\hline $\begin{array}{r}.6 \ldots \ldots \\
.7 \ldots \ldots \\
.8 \ldots \ldots \\
.9 \ldots \\
1.0 \ldots \ldots\end{array}$ & $\begin{array}{l}.5442 \\
.5815 \\
.6134 \\
.6410 \\
.6650\end{array}$ & $\begin{array}{l}.2627 \\
.2892 \\
.3126 \\
.3336 \\
.3524\end{array}$ & $\begin{array}{l}.2814 \\
.2923 \\
.3007 \\
.3074 \\
.3126\end{array}$ & $\begin{array}{l}9.60 \\
9.06 \\
8.57 \\
8.13 \\
7.73\end{array}$ & $\begin{array}{r}.6516 \\
6146 \\
.5815 \\
.5517 \\
.5244\end{array}$ & $\begin{array}{r}.6 \ldots \ldots \\
.7 \ldots \ldots \\
.8 \ldots \ldots \\
.9 \ldots \ldots \\
1.0 \ldots \ldots\end{array}$ & $\begin{array}{l}.7699 \\
.7407 \\
.7136 \\
.6884 \\
.6650\end{array}$ & $\begin{array}{l}.4404 \\
.4149 \\
.3919 \\
.3712 \\
.3524\end{array}$ & $\begin{array}{l}.3295 \\
.3258 \\
.3217 \\
.3172 \\
.3126\end{array}$ & $\begin{array}{l}5.80 \\
6.37 \\
6.88 \\
7.33 \\
7.73\end{array}$ & $\begin{array}{l}.3932 \\
.4321 \\
.4665 \\
.4971 \\
.5244\end{array}$ \\
\hline
\end{tabular}

\begin{tabular}{|c|c|c|c|c|c|c|c|c|c|c|c|}
\hline \multicolumn{12}{|c|}{$\frac{c}{2 a}=1.0$} \\
\hline $\begin{array}{r}0.1 \ldots \ldots \\
0.2 \ldots \ldots \\
.3 \ldots \ldots \\
.4 \ldots \ldots \\
.5 \ldots \ldots\end{array}$ & $\begin{array}{l}0 \\
0.2033 \\
.3198 \\
.4053 \\
.4719 \\
.5255\end{array}$ & $\begin{array}{l}0 \\
0.0645 \\
.1189 \\
.1654 \\
.2055 \\
.2403\end{array}$ & $\begin{array}{l}0 \\
0.1388 \\
.2009 \\
.2399 \\
.2664 \\
.2852\end{array}$ & $\begin{array}{r}13.94 \\
12.74 \\
11.74 \\
10.88 \\
10.14 \\
9.48\end{array}$ & $\begin{array}{r}1.0000 \\
0.9136 \\
.8421 \\
.7807 \\
.7274 \\
.6805\end{array}$ & $\begin{array}{r}0 \\
0.1 \ldots \ldots \\
.2 \ldots \ldots \\
.3 \ldots \ldots \\
.4 \ldots \ldots \\
.5 \ldots \ldots\end{array}$ & $\begin{array}{r}1.0000 \\
.9588 \\
.9201 \\
.8838 \\
.8498 \\
.8181\end{array}$ & $\begin{array}{r}0.6667 \\
.6200 \\
.5778 \\
.5397 \\
.5054 \\
.4746\end{array}$ & $\begin{array}{l}0.3333 \\
.3388 \\
.3423 \\
.3441 \\
.3445 \\
.3436\end{array}$ & $\begin{array}{r}0 \\
1.22 \\
2.28 \\
3.20 \\
3.99 \\
4.68\end{array}$ & $\begin{array}{l}0 \\
0.0878 \\
.1636 \\
.2293 \\
.2863 \\
.3360\end{array}$ \\
\hline $\begin{array}{r}.6 \\
7 \ldots \ldots \\
.8 \\
1.0 \ldots \ldots\end{array}$ & $\begin{array}{l}.5697 \\
.6067 \\
.6381 \\
.6650 \\
.6884\end{array}$ & $\begin{array}{l}.2707 \\
.2972 \\
.3207 \\
.3416 \\
.3603\end{array}$ & $\begin{array}{l}.2990 \\
.3995 \\
.3174 \\
.3234 \\
.3281\end{array}$ & $\begin{array}{l}8.90 \\
8.38 \\
7.91 \\
7.49 \\
7.11\end{array}$ & $\begin{array}{l}.6386 \\
.6012 \\
.5676 \\
.5375 \\
.5102\end{array}$ & $\begin{array}{r}.6 \ldots \ldots \\
.7 \ldots \ldots \\
.8 \ldots \ldots \\
.9 \ldots \ldots \\
1.0 \ldots \ldots\end{array}$ & $\begin{array}{l}.7885 \\
.7609 \\
.7351 \\
.7110 \\
.6884\end{array}$ & $\begin{array}{l}.4469 \\
.4219 \\
.3993 \\
.3789 \\
.3603\end{array}$ & $\begin{array}{l}.3417 \\
.3390 \\
.3358 \\
.3321 \\
.3281\end{array}$ & $\begin{array}{l}5.29 \\
5.83 \\
6.31 \\
6.73 \\
7.11\end{array}$ & $\begin{array}{l}.3797 \\
.4182 \\
.4524 \\
.4829 \\
.5102\end{array}$ \\
\hline
\end{tabular}


480 Scientific Papers of the Bureau of Standards. [Vol. 18

TABLE 2.-Values of Nagaoka's Constant $\mathrm{K}$ for Use in Formula 2

\begin{tabular}{|c|c|c|c|c|c|c|c|c|c|c|c|}
\hline$\frac{2 a}{b}$ & $K$ & $\Delta$ & $\frac{2 a}{b}$ & $K$ & $\Delta$ & $\frac{2 a}{b}$ & $K$ & $\Delta$ & $\frac{2 a}{b}$ & $K$ & $\Delta$ \\
\hline $\begin{array}{c}0.00 \ldots . . . \\
.01 \ldots . . \\
.02 \ldots . \\
.03 \ldots \\
.04 \ldots .\end{array}$ & $\begin{array}{r}1.00000 \\
.99577 \\
.99156 \\
.98738 \\
.98322\end{array}$ & $\begin{array}{r}-423 \\
421 \\
418 \\
416 \\
413\end{array}$ & $\begin{array}{r}0.50 \ldots \\
.51 \ldots \\
.52 \ldots \\
.53 \ldots \\
.54 \ldots\end{array}$ & $\begin{array}{r}0.81814 \\
.81508 \\
.81205 \\
.80904 \\
.80605\end{array}$ & $\begin{array}{r}-305 \\
303 \\
301 \\
299 \\
297\end{array}$ & $\begin{array}{l}1.00 \ldots \\
1.05 \ldots \\
1.10 \ldots \\
1.15 \ldots \\
1.20 \ldots\end{array}$ & $\begin{array}{r}0.68842 \\
.67770 \\
.66732 \\
.65726 \\
.64753\end{array}$ & $\begin{array}{r}-1073 \\
1038 \\
1005 \\
974 \\
943\end{array}$ & $\begin{array}{l}5.00 \ldots \\
5.50 \ldots \\
6.00 \ldots \\
6.50 \ldots \\
7.00 \ldots\end{array}$ & $\begin{array}{r}0.31982 \\
.30150 \\
.28541 \\
.27115 \\
.25841\end{array}$ & $\begin{array}{r}-1832 \\
1609 \\
1426 \\
1274 \\
1146\end{array}$ \\
\hline $\begin{array}{l}.05 \ldots . . \\
.06 \ldots . . . \\
.07 \ldots . . \\
.08 \ldots . . \\
.09 \ldots\end{array}$ & $\begin{array}{r}.97909 \\
.97498 \\
.97090 \\
.96685 \\
.96282\end{array}$ & $\begin{array}{l}411 \\
408 \\
406 \\
403 \\
401\end{array}$ & $\begin{array}{l}.55 \ldots \\
.56 \ldots \\
.57 \ldots \\
.58 \ldots \\
.59 \ldots \\
\end{array}$ & $\begin{array}{r}.80308 \\
.80012 \\
.79720 \\
.79428 \\
.79140\end{array}$ & $\begin{array}{l}295 \\
293 \\
291 \\
289 \\
287\end{array}$ & $\begin{array}{l}1.25 \ldots \\
1.30 \ldots \\
1.35 \ldots \\
1.40 \ldots \\
1.45 \ldots\end{array}$ & $\begin{array}{l}.63809 \\
.62895 \\
.62009 \\
.61149 \\
.60314\end{array}$ & $\begin{array}{l}914 \\
886 \\
860 \\
834 \\
810\end{array}$ & $\begin{array}{l}7.50 \ldots \\
8.00 \ldots \\
8.50 \ldots \\
9.00 \ldots \\
9.50 \ldots\end{array}$ & $\begin{array}{l}.24695 \\
.23658 \\
.22715 \\
.21853 \\
.21062\end{array}$ & $\begin{array}{r}1037 \\
943 \\
862 \\
791 \\
729\end{array}$ \\
\hline $\begin{array}{l}.10 \ldots \\
.11 \ldots \\
.12 \ldots \\
.13 \ldots \\
.14 \ldots\end{array}$ & $\begin{array}{l}.95881 \\
.95482 \\
.95087 \\
.94694 \\
.94302\end{array}$ & $\begin{array}{l}398 \\
396 \\
393 \\
391 \\
388\end{array}$ & $\begin{array}{l}.60 \ldots \\
.61 \ldots \\
.62 \ldots \\
.63 \ldots \\
.64 \ldots\end{array}$ & $\begin{array}{l}.78852 \\
.78568 \\
.78284 \\
.78003 \\
.77724\end{array}$ & $\begin{array}{l}285 \\
283 \\
281 \\
279 \\
277\end{array}$ & $\begin{array}{l}1.50 \ldots \\
1.55 \ldots \\
1.60 \ldots \\
1.65 \ldots \\
1.70 \ldots\end{array}$ & $\begin{array}{r}.59504 \\
.58718 \\
.57954 \\
.57212 \\
.56490\end{array}$ & $\begin{array}{l}786 \\
764 \\
742 \\
722 \\
702\end{array}$ & $\begin{array}{l}10.00 \ldots \\
11.0 \ldots \\
12.0 \ldots \\
13.0 \ldots \\
14.0 \ldots\end{array}$ & $\begin{array}{l}.20332 \\
.19031 \\
.17904 \\
.16916 \\
.16043\end{array}$ & $\begin{array}{r}1301 \\
1127 \\
988 \\
873 \\
778\end{array}$ \\
\hline $\begin{array}{l}.15 . \\
.16 \\
.17 \\
.18 \\
.19\end{array}$ & $\begin{array}{l}.93914 \\
.93528 \\
.93145 \\
.92764 \\
.92385\end{array}$ & $\begin{array}{l}386 \\
383 \\
381 \\
378 \\
376\end{array}$ & $\begin{array}{l}.65 \ldots \\
.66 \ldots \\
.67 \ldots \\
.68 \ldots \\
.69 \ldots\end{array}$ & $\begin{array}{r}.77447 \\
.77171 \\
.76898 \\
.76626 \\
.76356\end{array}$ & $\begin{array}{l}275 \\
274 \\
272 \\
270 \\
268\end{array}$ & $\begin{array}{l}1.75 \ldots \\
1.80 \ldots \\
1.85 \ldots \\
1.90 \ldots \\
1.95 \ldots\end{array}$ & $\begin{array}{r}.55788 \\
.55106 \\
.54441 \\
.53794 \\
.53165\end{array}$ & $\begin{array}{l}683 \\
664 \\
647 \\
630 \\
614\end{array}$ & $\begin{array}{l}15.0 \ldots \\
16.0 . . \\
17.0 . . \\
18.0 . . \\
19.0 \ldots\end{array}$ & $\begin{array}{r}.15265 \\
.14567 \\
.13936 \\
.13363 \\
.12841\end{array}$ & $\begin{array}{l}698 \\
631 \\
573 \\
522 \\
479\end{array}$ \\
\hline $\begin{array}{l}.20 \ldots \\
.21 \ldots \\
.22 \ldots \\
.23 \ldots \\
.24 \ldots\end{array}$ & $\begin{array}{l}.92009 \\
.91636 \\
.91264 \\
.90895 \\
.90529\end{array}$ & $\begin{array}{l}374 \\
371 \\
369 \\
366 \\
364\end{array}$ & $\begin{array}{l}.70 \ldots \\
.71 \ldots \\
.72 \ldots \\
.73 \ldots \\
.74 \ldots\end{array}$ & $\begin{array}{l}.76089 \\
.75822 \\
.75558 \\
.75296 \\
.75035\end{array}$ & $\begin{array}{l}266 \\
264 \\
262 \\
261 \\
259\end{array}$ & $\begin{array}{l}2.00 \ldots \\
2.10 \ldots \\
2.20 \ldots \\
2.30 \ldots \\
2.40 \ldots\end{array}$ & $\begin{array}{r}.52551 \\
.51370 \\
.50247 \\
.49178 \\
.48159\end{array}$ & $\begin{array}{r}1181 \\
1123 \\
1069 \\
1019 \\
973\end{array}$ & $\begin{array}{l}20.0 \ldots \\
22.0 \ldots \\
24.0 \ldots \\
26.0 \ldots \\
28.0 \ldots\end{array}$ & $\begin{array}{r}.12352 \\
.11508 \\
.10784 \\
.10150 \\
.09593\end{array}$ & $\begin{array}{l}854 \\
724 \\
634 \\
557 \\
493\end{array}$ \\
\hline $\begin{array}{l}.25 \ldots \ldots \\
.26 \ldots \ldots \\
.27 \ldots \ldots \\
.28 \ldots \ldots \\
.29 \ldots\end{array}$ & $\begin{array}{r}.90165 \\
.89803 \\
.89444 \\
.89087 \\
.88732\end{array}$ & $\begin{array}{l}362 \\
359 \\
357 \\
355 \\
352\end{array}$ & $\begin{array}{l}.75 \ldots \\
.76 \ldots \\
.77 \ldots \\
.78 \ldots \\
.79 \ldots\end{array}$ & $\begin{array}{l}.74776 \\
.74519 \\
.74264 \\
.74010 \\
.73758\end{array}$ & $\begin{array}{l}257 \\
255 \\
254 \\
252 \\
250\end{array}$ & $\begin{array}{l}2.50 \ldots \\
2.60 \ldots \\
2.70 \ldots \\
2.80 \ldots \\
2.90 \ldots\end{array}$ & $\begin{array}{l}.47186 \\
.46257 \\
.45369 \\
.44518 \\
.43702\end{array}$ & $\begin{array}{l}929 \\
889 \\
851 \\
815 \\
782\end{array}$ & $\begin{array}{l}30.0 \ldots \\
32.0 \ldots \\
34.0 \ldots \\
36.0 \ldots \\
38.0 \ldots\end{array}$ & $\begin{array}{l}.09100 \\
.08659 \\
.08203 \\
.07905 \\
.07580\end{array}$ & $\begin{array}{l}441 \\
396 \\
358 \\
325 \\
298\end{array}$ \\
\hline $\begin{array}{l}.30 \ldots \ldots \\
.31 \ldots \ldots \\
.32 \ldots \ldots \\
.33 \ldots \ldots \\
.34 \ldots \ldots\end{array}$ & $\begin{array}{r}.88380 \\
.88030 \\
.87683 \\
.87338 \\
.86995\end{array}$ & $\begin{array}{l}350 \\
348 \\
345 \\
343 \\
341\end{array}$ & $\begin{array}{l}.80 \ldots \\
.81 \ldots \\
.82 \ldots \\
.83 \ldots \\
.84 \ldots\end{array}$ & $\begin{array}{l}.73508 \\
.73259 \\
.73013 \\
.72768 \\
.72524\end{array}$ & $\begin{array}{l}249 \\
247 \\
245 \\
244 \\
242\end{array}$ & $\begin{array}{l}3.00 \ldots \\
3.10 \ldots \\
3.20 \ldots \\
3.30 \ldots \\
3.40 . .\end{array}$ & $\begin{array}{r}.42920 \\
.42169 \\
.41447 \\
.40752 \\
.40084\end{array}$ & $\begin{array}{l}751 \\
722 \\
694 \\
668 \\
644\end{array}$ & $\begin{array}{l}40.0 \ldots \\
50.0 \ldots \\
60.0 \ldots \\
70.0 \ldots \\
80.0 \ldots\end{array}$ & $\begin{array}{l}.07282 \\
.06110 \\
.05285 \\
.04670 \\
.04192\end{array}$ & $\begin{array}{r}1172 \\
825 \\
615 \\
478 \\
382\end{array}$ \\
\hline $\begin{array}{l}35 . \\
.36 \\
.37 \\
.38 . \\
.39\end{array}$ & $\begin{array}{l}.86654 \\
.86316 \\
.85980 \\
.85646 \\
.85315\end{array}$ & $\begin{array}{l}338 \\
336 \\
334 \\
332 \\
329\end{array}$ & $\begin{array}{l}.85 \\
.86 \\
.87 \\
.88 \\
.89\end{array}$ & $\begin{array}{r}.72282 \\
.72042 \\
.71803 \\
.71566 \\
.71331\end{array}$ & $\begin{array}{l}240 \\
239 \\
237 \\
236 \\
234\end{array}$ & $\begin{array}{l}3.50 \ldots \\
3.60 \ldots \\
3.70 \ldots \\
3.80 \ldots \\
3.90 \ldots\end{array}$ & $\begin{array}{l}.39440 \\
.38819 \\
.38220 \\
.37642 \\
.37083\end{array}$ & $\begin{array}{l}621 \\
599 \\
578 \\
559 \\
540\end{array}$ & $\begin{array}{l}90.0 \ldots \\
100.0 . \\
200.0 \ldots \\
400.0 . \\
\ldots \ldots\end{array}$ & $\begin{array}{r}.03810 \\
.03496 \\
.01969 \\
.01095\end{array}$ & $\begin{array}{l}314 \\
\cdots \ldots \\
\cdots \cdots \\
\cdots \cdots\end{array}$ \\
\hline $\begin{array}{l}.40 . \\
.41 . \\
.42 . \\
.43 . \\
.44 .\end{array}$ & $\begin{array}{l}.84985 \\
.84653 \\
.84334 \\
.84011 \\
.83691\end{array}$ & $\begin{array}{l}327 \\
325 \\
322 \\
320 \\
318\end{array}$ & $\begin{array}{l}.90 \ldots \\
.91 \ldots \\
.92 \ldots \\
.93 \ldots \\
.94 \ldots\end{array}$ & $\begin{array}{l}.71097 \\
.70865 \\
.70634 \\
.70405 \\
.70177\end{array}$ & $\begin{array}{l}232 \\
231 \\
229 \\
228 \\
226\end{array}$ & $\begin{array}{l}4.00 \ldots \\
4.10 \ldots \\
4.20 \ldots \\
4.30 \ldots \\
4.40 \ldots\end{array}$ & $\begin{array}{l}.36543 \\
.36021 \\
.35515 \\
.35025 \\
.34550\end{array}$ & $\begin{array}{l}523 \\
506 \\
489 \\
475 \\
460\end{array}$ & & & \\
\hline $\begin{array}{r}45 \ldots . . \\
.46 \ldots \\
.47 \ldots \ldots \\
.48 \ldots . \\
.49 \ldots .\end{array}$ & $\begin{array}{l}.83372 \\
.83056 \\
.82742 \\
.82431 \\
.82121\end{array}$ & $\begin{array}{l}316 \\
314 \\
312 \\
310 \\
308\end{array}$ & $\begin{array}{l}.95 \ldots . \\
.96 \ldots \\
.97 \ldots \\
.98 \ldots \\
.99 . \ldots\end{array}$ & $\begin{array}{l}.69951 \\
.69726 \\
.69503 \\
.69281 \\
.69061\end{array}$ & $\begin{array}{l}225 \\
223 \\
222 \\
220 \\
219\end{array}$ & $\begin{array}{l}4.50 \ldots \\
4.60 \ldots \\
4.70 \ldots \\
4.80 \ldots \\
4.90 . .\end{array}$ & $\begin{array}{r}.34090 \\
.33643 \\
.33210 \\
.32789 \\
.32380\end{array}$ & $\begin{array}{l}447 \\
433 \\
421 \\
409 \\
398\end{array}$ & & & $\begin{array}{l}\ldots \\
\cdots \\
\cdots\end{array}$ \\
\hline $.50 \ldots$ & .81814 & 305 & $1.00 .$. & .68842 & & $5.00 \ldots$ & .31982 & & & & \\
\hline
\end{tabular}


TABLE 3.- Values of the Quantity $P$ for Use in Formula 4 and for Disk Coils of Negligible Thickness

\begin{tabular}{|c|c|c|c|c|c|c|c|c|c|c|c|}
\hline$\frac{c}{2 a}$ & $P$ & $\Delta$ & $\frac{c}{2 a}$ & $P$ & $\Delta$ & $\frac{c}{2 a}$ & $P$ & $\Delta$ & $\frac{c}{2 a}$ & $P$ & $\Delta$ \\
\hline $\begin{array}{r}0.01 \ldots \ldots \\
.02 \ldots \ldots \\
.03 \ldots \ldots\end{array}$ & $\begin{array}{l}\infty \\
69.008 \\
60.299 \\
55.206 \\
51.595\end{array}$ & $\begin{array}{l}8709 \\
5093 \\
3611 \\
2801\end{array}$ & $\begin{array}{r}0.25 \ldots \\
.26 \ldots \\
.27 \ldots \\
.28 \ldots \\
.29 \ldots\end{array}$ & $\begin{array}{l}28.767 \\
28.290 \\
27.832 \\
27.392 \\
26.968\end{array}$ & $\begin{array}{l}477 \\
458 \\
440 \\
424 \\
408\end{array}$ & $\begin{array}{r}0.50 \ldots \\
.51 \ldots \\
.52 \ldots \\
.53 \ldots \\
.54 \ldots\end{array}$ & $\begin{array}{l}20.601 \\
20.381 \\
20.165 \\
19.955 \\
19.750\end{array}$ & $\begin{array}{l}221 \\
216 \\
210 \\
205 \\
200\end{array}$ & $\begin{array}{r}0.75 \ldots \\
.76 \ldots \\
.77 \ldots \\
.78 \ldots \\
.79 \ldots\end{array}$ & $\begin{array}{l}16.360 \\
16.235 \\
16.112 \\
15.992 \\
15.874\end{array}$ & $\begin{array}{l}125 \\
123 \\
120 \\
118 \\
115\end{array}$ \\
\hline $\begin{array}{l}.05 \ldots \ldots \\
.06 \ldots \ldots \\
.07 \ldots \ldots \\
.08 \ldots \ldots \\
.09 \ldots \ldots\end{array}$ & $\begin{array}{l}48.794 \\
46.507 \\
44.574 \\
42.902 \\
41.428\end{array}$ & $\begin{array}{l}2287 \\
1933 \\
1672 \\
1474 \\
1317\end{array}$ & $\begin{array}{l}.30 \ldots \\
.31 \ldots \\
.32 \ldots \\
.33 \ldots \\
.34 \ldots\end{array}$ & $\begin{array}{l}26.560 \\
26.166 \\
25.786 \\
25.418 \\
25.063\end{array}$ & $\begin{array}{l}394 \\
380 \\
368 \\
355 \\
344\end{array}$ & $\begin{array}{l}.55 \ldots \\
.56 \ldots \\
.57 \ldots \\
.58 \ldots \\
.59 \ldots\end{array}$ & $\begin{array}{l}19.550 \\
19.354 \\
19.162 \\
18.976 \\
18.793\end{array}$ & $\begin{array}{l}196 \\
192 \\
187 \\
183 \\
179\end{array}$ & $\begin{array}{l}.80 \ldots \\
.81 \ldots \\
.82 \ldots \\
.83 \ldots \\
.84 \ldots\end{array}$ & $\begin{array}{l}15.759 \\
15.646 \\
15.536 \\
15.428 \\
15.323\end{array}$ & $\begin{array}{l}113 \\
110 \\
108 \\
105 \\
103\end{array}$ \\
\hline $\begin{array}{l}.10 \ldots \ldots \\
.11 \ldots \ldots \\
.12 \ldots \ldots \\
.13 \ldots \ldots \\
.14 \ldots \ldots\end{array}$ & $\begin{array}{l}40.111 \\
38.920 \\
37.835 \\
36.838 \\
35.916\end{array}$ & $\begin{array}{r}1191 \\
1085 \\
997 \\
922 \\
858\end{array}$ & $\begin{array}{l}.35 \ldots \\
.36 \ldots \\
.37 \ldots \\
.38 \ldots \\
.39 \ldots \\
\end{array}$ & $\begin{array}{l}24.719 \\
24.386 \\
24.063 \\
23.750 \\
23.446\end{array}$ & $\begin{array}{l}333 \\
323 \\
313 \\
304 \\
296\end{array}$ & $\begin{array}{l}.60 \ldots \\
.61 \ldots \\
.62 \ldots \\
.63 \ldots \\
.64 \ldots\end{array}$ & $\begin{array}{l}18.614 \\
18.440 \\
18.269 \\
18.102 \\
17.939\end{array}$ & $\begin{array}{l}174 \\
171 \\
167 \\
163 \\
160\end{array}$ & $\begin{array}{l}.85 \ldots \\
.86 \ldots \\
.87 \ldots \\
.88 \ldots \\
.89 \ldots\end{array}$ & $\begin{array}{l}15.220 \\
15.119 \\
15.021 \\
14.925 \\
14.832\end{array}$ & $\begin{array}{r}101 \\
98 \\
96 \\
94 \\
92\end{array}$ \\
\hline $\begin{array}{l}15 \ldots \ldots \\
.16 \ldots \ldots \\
.17 \ldots \\
.18 \ldots \\
.19 \ldots\end{array}$ & $\begin{array}{l}35.058 \\
34.258 \\
33.507 \\
32.800 \\
32.132\end{array}$ & $\begin{array}{l}800 \\
751 \\
707 \\
668 \\
632\end{array}$ & $\begin{array}{l}.40 \ldots \\
.41 \ldots \\
.42 \ldots \\
.43 \ldots \\
.44 \ldots\end{array}$ & $\begin{array}{l}23.150 \\
22.863 \\
22.584 \\
22.313 \\
22.049\end{array}$ & $\begin{array}{l}287 \\
279 \\
271 \\
264 \\
257\end{array}$ & $\begin{array}{l}.65 \ldots \\
.66 \ldots \\
.67 \ldots \\
.68 \ldots \\
.69 \ldots\end{array}$ & $\begin{array}{l}17.779 \\
17.623 \\
17.470 \\
17.320 \\
17.174\end{array}$ & $\begin{array}{l}156 \\
153 \\
150 \\
146 \\
142\end{array}$ & $\begin{array}{l}.90 \ldots \\
.91 \ldots \\
.92 \ldots \\
.93 \ldots \\
.94 \ldots\end{array}$ & $\begin{array}{l}14.740 \\
14.650 \\
14.563 \\
14.478 \\
14.394\end{array}$ & $\begin{array}{l}90 \\
87 \\
85 \\
83 \\
80\end{array}$ \\
\hline $\begin{array}{l}.20 \ldots \ldots \\
.21 \ldots \ldots \\
.22 \ldots \ldots \\
.23 \ldots \ldots \\
.24 \ldots \ldots\end{array}$ & $\begin{array}{l}31.500 \\
30.900 \\
30.330 \\
29.785 \\
29.265\end{array}$ & $\begin{array}{l}600 \\
570 \\
545 \\
520 \\
498\end{array}$ & $\begin{array}{l}.45 \ldots \\
.46 \ldots \\
.47 \ldots \\
.48 \ldots \\
.49 \ldots\end{array}$ & $\begin{array}{l}21.792 \\
21.541 \\
21.297 \\
21.059 \\
20.827\end{array}$ & $\begin{array}{l}251 \\
244 \\
238 \\
232 \\
226\end{array}$ & $\begin{array}{l}.70 \ldots \\
.71 \ldots \\
.72 \ldots \\
.73 \ldots \\
.74 \ldots\end{array}$ & $\begin{array}{l}17.032 \\
16.891 \\
16.754 \\
16.620 \\
16.489\end{array}$ & $\begin{array}{l}141 \\
137 \\
134 \\
131 \\
129\end{array}$ & $\begin{array}{l}.95 \ldots \\
.96 \ldots \\
.97 \ldots \\
.98 \ldots \\
.99 \ldots\end{array}$ & $\begin{array}{l}14.314 \\
14.235 \\
14.158 \\
14.083 \\
14.010\end{array}$ & $\begin{array}{l}79 \\
77 \\
75 \\
73 \\
71\end{array}$ \\
\hline $.25 \ldots$ & 28.767 & 477 & $.50 \ldots$ & 20.601 & 221 & $.75 \ldots$ & 16.360 & 125 & $1.00 \ldots$ & 13.939 & \\
\hline
\end{tabular}

TABLE 4. $a$ - Constants for Insulation Correction for Flat Spirals (Values of $\delta$ )

\begin{tabular}{|c|c|c|c|c|c|c|c|c|c|c|c|}
\hline \multirow{2}{*}{$\nu$} & \multicolumn{6}{|c|}{ Values of $\delta_{12}$} & \multirow{2}{*}{$\nu$} & \multicolumn{4}{|c|}{ Values of $\delta_{13}$} \\
\hline & $\tau=0$ & 0.1 & 0.3 & 0.5 & 0.7 & 0.9 & & $\tau=0$ & 0.3 & 0.6 & 0.9 \\
\hline $\begin{array}{l}0 . \ldots \ldots \\
0.5 \ldots \ldots \\
1.0 \ldots \ldots \\
1.5 \ldots \ldots \\
2.0 \ldots \ldots\end{array}$ & $\begin{array}{l}0.114 \\
.090 \\
.064 \\
.047 \\
.035\end{array}$ & $\begin{array}{l}0.113 \\
.089 \\
.061 \\
.047 \\
.035\end{array}$ & $\begin{array}{l}0.106 \\
.083 \\
.059 \\
.043 \\
.032\end{array}$ & $\begin{array}{l}0.092 \\
.070 \\
.050 \\
.036 \\
.027\end{array}$ & $\begin{array}{l}0.068 \\
.049 \\
.034 \\
.025 \\
.018\end{array}$ & $\begin{array}{l}0.030 \\
.020 \\
.013 \\
.009 \\
.007\end{array}$ & $\begin{array}{l}0 \ldots \ldots . \\
0.5 \ldots \ldots \\
1.0 \ldots \ldots \\
2.0 \ldots \ldots \\
4.0 \ldots \ldots\end{array}$ & $\begin{array}{l}0.022 \\
.021 \\
.019 \\
.015 \\
.008\end{array}$ & $\begin{array}{l}0.020 \\
.019 \\
.018 \\
.015 \\
.008\end{array}$ & $\begin{array}{l}0.014 \\
.014 \\
.013 \\
.010 \\
.005\end{array}$ & $\begin{array}{l}0.004 \\
.004 \\
.004 \\
.003 \\
.002\end{array}$ \\
\hline $\begin{array}{r}3.0 \ldots \ldots \\
4.0 \ldots \ldots \\
6.0 \ldots \ldots \\
8.0 \ldots \ldots \\
10.0 \ldots \ldots\end{array}$ & $\begin{array}{l}.022 \\
.015 \\
.008 \\
.006 \\
.004\end{array}$ & $\begin{array}{l}.022 \\
.015 \\
.008 \\
.006 \\
.004\end{array}$ & $\begin{array}{l}.020 \\
.014 \\
.008 \\
.005 \\
.004\end{array}$ & $\begin{array}{l}.017 \\
.012 \\
.006 \\
.004 \\
.003\end{array}$ & $\begin{array}{l}.011 \\
.008 \\
.004 \\
.003 \\
.002\end{array}$ & $\begin{array}{l}.004 \\
.003 \\
.002 \\
.001 \\
.001\end{array}$ & $\begin{array}{r}6.0 \ldots \ldots \\
10.0 \ldots \ldots\end{array}$ & $\begin{array}{l}.005 \\
.003\end{array}$ & $\begin{array}{l}.005 \\
.003\end{array}$ & $\begin{array}{l}.004 \\
.002\end{array}$ & .001 \\
\hline \multirow{2}{*}{\multicolumn{2}{|c|}{$u$}} & \multicolumn{4}{|c|}{ Values of $\delta_{34}$} & & \multicolumn{4}{|c|}{ Values of $\delta_{15}$} \\
\hline & & $\tau=0$ & 0.3 & 0.6 & 0.9 & & & $\tau=0$ & 0.1 & 0.5 & 0.9 \\
\hline $\begin{array}{r}0 \ldots . \\
1 \ldots . \\
3 \ldots \\
5 \ldots \\
10 \ldots\end{array}$ & & $\begin{array}{l}0.009 \\
.009 \\
.007 \\
.004 \\
.002\end{array}$ & $\begin{array}{l}0.009 \\
.008 \\
.006 \\
.004 \\
.002\end{array}$ & $\begin{array}{l}0.006 \\
.006 \\
.004 \\
.003 \\
.001\end{array}$ & $\begin{array}{l}0.002 \\
.002 \\
.001 \\
.001 \\
.000\end{array}$ & $\begin{array}{c}0 \ldots . \\
5 \ldots \\
10 \ldots\end{array}$ & & $\begin{array}{r}0.005 \\
.003 \\
.002\end{array}$ & $\begin{array}{l}0.005 \\
.003 \\
.002\end{array}$ & $\begin{array}{r}0.004 \\
.002 \\
.001\end{array}$ & $\begin{array}{r}0.001 \\
.001\end{array}$ \\
\hline
\end{tabular}

a The maximum values of the $\delta$ 's of higher order are $0.00 \mathrm{r}$ or less. 
TABLE 4-Constants for Insulation Correction for Flat Spirals (Value of $\delta$ )-Con.

\begin{tabular}{|c|c|c|c|c|c|c|c|c|c|c|c|}
\hline \multirow{2}{*}{$y$} & \multicolumn{3}{|c|}{ Values of $\delta_{15}$} & \multirow{2}{*}{$\nu$} & \multicolumn{3}{|c|}{ Values of $\delta_{17}$} & \multirow{2}{*}{$\nu$} & \multicolumn{3}{|c|}{ Values of $\delta_{18}$} \\
\hline & $\begin{array}{c}r=0 \\
\text { and } 0.1\end{array}$ & 0.5 & 0.9 & & $\begin{array}{c}\tau=0 \\
\text { and } 0.1\end{array}$ & 0.5 & 0.9 & & $\begin{aligned} \tau & =0 \\
\text { and } & 0.1\end{aligned}$ & 0.5 & 0.9 \\
\hline $\begin{array}{r}0 \ldots \ldots . \\
5 \ldots \ldots .\end{array}$ & $\begin{array}{r}0.003 \\
.002 \\
.001\end{array}$ & $\begin{array}{r}0.003 \\
.002 \\
.001\end{array}$ & $\begin{array}{r}0.001 \\
.000 \\
.000\end{array}$ & $\begin{array}{r}0 \ldots \ldots \\
5 \ldots \ldots \\
10 \ldots \ldots\end{array}$ & $\begin{array}{r}0.002 \\
.002 \\
.001\end{array}$ & $\begin{array}{r}0.002 \\
.001 \\
.001\end{array}$ & $\begin{array}{r}0.001 \\
.000 \\
.000\end{array}$ & $\begin{array}{r}0 \ldots \ldots . \\
5 \ldots \ldots \\
10 \ldots \ldots\end{array}$ & $\begin{array}{r}0.002 \\
.001 \\
.001\end{array}$ & $\begin{array}{r}0.001 \\
.001 \\
.001\end{array}$ & $\begin{array}{r}0.000 \\
.000 \\
.000\end{array}$ \\
\hline
\end{tabular}

TABLE 5.-Binomial Coefficients for Interpolation by Differences

\begin{tabular}{|c|c|c|c|c|c|c|c|c|c|c|c|}
\hline$H_{1}$ & $H_{2}$ & $\mathrm{HI}_{3}$ & $H_{1}$ & $H_{2}$ & $H_{3}$ & $H_{1}$ & $\mathrm{H}_{2}$ & $H_{3}$ & $H_{1}$ & $H_{2}$ & $H_{3}$ \\
\hline $\begin{array}{r}0.01 \ldots . \\
.02 \ldots \\
.03 \ldots \\
.04 \ldots \\
.05 \ldots\end{array}$ & $\begin{array}{r}-0.005 \\
.010 \\
.015 \\
.019 \\
.024\end{array}$ & $\begin{array}{r}+0.003 \\
.006 \\
.010 \\
.013 \\
.015\end{array}$ & $\begin{array}{r}0.26 \ldots \\
.27 \ldots \\
.28 \ldots \\
.29 \ldots \\
.30 \ldots\end{array}$ & $\begin{array}{r}-0.096 \\
.099 \\
.101 \\
.103 \\
.105\end{array}$ & $\begin{array}{r}+0.056 \\
.057 \\
.058 \\
.059 \\
.060\end{array}$ & $\begin{array}{r}0.51 \ldots \\
.52 \ldots \\
.53 \ldots \\
.54 \ldots \\
.55 \ldots\end{array}$ & $\begin{array}{r}-0.125 \\
.125 \\
.125 \\
.124 \\
.124\end{array}$ & $\begin{array}{r}+0.062 \\
.062 \\
.061 \\
.060 \\
.060\end{array}$ & $\begin{array}{r}0.76 \ldots \\
.77 \ldots \\
.78 \ldots \\
.79 \ldots \\
.80 \ldots\end{array}$ & $\begin{array}{r}-0.091 \\
.089 \\
.086 \\
.083 \\
.080\end{array}$ & $\begin{array}{r}+0.038 \\
.036 \\
.035 \\
.033 \\
.032\end{array}$ \\
\hline $\begin{array}{l}.06 \ldots . . \\
.07 \ldots \\
.08 \ldots \\
.09 \ldots \\
.10 \ldots\end{array}$ & $\begin{array}{l}.028 \\
.033 \\
.037 \\
.041 \\
.045\end{array}$ & $\begin{array}{l}.018 \\
.021 \\
.024 \\
.026 \\
.028\end{array}$ & $\begin{array}{l}.31 \ldots \\
.32 \ldots \\
.33 \ldots \\
.34 \ldots \\
.35 \ldots\end{array}$ & $\begin{array}{l}.107 \\
.109 \\
.111 \\
.112 \\
.114\end{array}$ & $\begin{array}{l}.060 \\
.061 \\
.062 \\
.052 \\
.063\end{array}$ & & $\begin{array}{l}.124 \\
.123 \\
.122 \\
.121 \\
.120\end{array}$ & $\begin{array}{l}.059 \\
.058 \\
.058 \\
.057 \\
.056\end{array}$ & & $\begin{array}{l}.077 \\
.074 \\
.071 \\
.067 \\
.064\end{array}$ & $\begin{array}{l}.031 \\
.029 \\
.028 \\
.026 \\
.024\end{array}$ \\
\hline $\begin{array}{l}.11 \ldots \ldots \\
.12 \ldots \ldots \\
.13 \ldots \ldots \\
.14 \ldots \ldots\end{array}$ & $\begin{array}{l}.049 \\
.053 \\
.057 \\
.060 \\
.054\end{array}$ & $\begin{array}{l}.031 \\
.033 \\
.035 \\
.037 \\
.039\end{array}$ & $\begin{array}{l}.36 \ldots \\
.37 \ldots \\
.38 \ldots \\
.39 \ldots \\
.40 \ldots\end{array}$ & $\begin{array}{r}.115 \\
.117 \\
.118 \\
.119 \\
.120\end{array}$ & $\begin{array}{l}.063 \\
.063 \\
.064 \\
.064 \\
.064\end{array}$ & & $\begin{array}{l}.119 \\
.118 \\
.117 \\
.115 \\
.114\end{array}$ & $\begin{array}{l}.055 \\
.054 \\
.053 \\
.052 \\
.051\end{array}$ & $\begin{array}{l}.85 \ldots \\
.87 \ldots \\
.88 \ldots \\
.89 \ldots \\
.90 \ldots\end{array}$ & $\begin{array}{l}.060 \\
.057 \\
.053 \\
.049 \\
.045\end{array}$ & $\begin{array}{l}.023 \\
.021 \\
.020 \\
.018 \\
.016\end{array}$ \\
\hline $\begin{array}{l}.16 \ldots . \\
.17 \ldots \\
.18 \ldots \\
.19 \ldots \\
.20 \ldots\end{array}$ & $\begin{array}{l}.067 \\
.071 \\
.074 \\
.077 \\
.080\end{array}$ & $\begin{array}{l}.041 \\
.043 \\
.045 \\
.046 \\
.048\end{array}$ & $\begin{array}{l}.41 \ldots \\
.42 \ldots \\
.43 \ldots \\
.44 \ldots \\
.45 \ldots\end{array}$ & $\begin{array}{l}.121 \\
.122 \\
.123 \\
.123 \\
.124\end{array}$ & $\begin{array}{l}.064 \\
.064 \\
.064 \\
.064 \\
.054\end{array}$ & $\begin{array}{l}.66 \ldots \\
.67 \ldots \\
.68 \ldots \\
.69 \ldots \\
.70 \ldots\end{array}$ & $\begin{array}{l}.112 \\
.111 \\
.109 \\
.107 \\
.105\end{array}$ & $\begin{array}{l}.050 \\
.049 \\
.048 \\
.047 \\
.045\end{array}$ & $\begin{array}{l}.91 \ldots \\
.92 \ldots \\
.93 \ldots \\
.94 \ldots \\
.95 \ldots\end{array}$ & $\begin{array}{l}.041 \\
.037 \\
.033 \\
.028 \\
.024\end{array}$ & $\begin{array}{l}.015 \\
.013 \\
.012 \\
.010 \\
.008\end{array}$ \\
\hline $\begin{array}{l}.21 \ldots \\
.22 \ldots \ldots \\
.23 \ldots \\
.24 \ldots \\
.25 \ldots\end{array}$ & $\begin{array}{l}.083 \\
.086 \\
.089 \\
.091 \\
.094\end{array}$ & $\begin{array}{l}.049 \\
.051 \\
.052 \\
.053 \\
.055\end{array}$ & $\begin{array}{l}.46 \ldots \\
.47 \ldots \\
.48 \ldots \\
.49 \ldots \\
.50 \ldots\end{array}$ & $\begin{array}{l}.124 \\
.125 \\
.125 \\
.125 \\
.125\end{array}$ & $\begin{array}{l}.064 \\
.064 \\
.063 \\
.063 \\
.063\end{array}$ & $\begin{array}{l}.71 . \\
.72 . \\
.73 . \\
.74 . \\
.75 . .\end{array}$ & $\begin{array}{l}.103 \\
.101 \\
.099 \\
.096 \\
.094\end{array}$ & $\begin{array}{l}.044 \\
.043 \\
.042 \\
.040 \\
.039\end{array}$ & $\begin{array}{r}.96 \ldots \\
.97 \ldots \\
.98 \ldots \\
.99 \ldots \\
1.00 \ldots\end{array}$ & $\begin{array}{l}.019 \\
.015 \\
.010 \\
.005 \\
.000\end{array}$ & $\begin{array}{l}.007 \\
.005 \\
.003 \\
.002 \\
.000\end{array}$ \\
\hline
\end{tabular}

\section{APPENDIX-COLLECTION OF FORMULAS USED IN THE PREPARATION OF THE TABLES}

LYLE'S FORMULA FOR SHORT, THIN COILS.-

$$
\begin{aligned}
& L_{\mathrm{u}}=0.00 \mathrm{I} n^{2} a P^{\prime} \\
& \begin{aligned}
P^{\prime}=4 \pi\left[\log _{\mathrm{e}} \frac{8 a}{d}\{\mathrm{I}\right. & \left.+m_{1} \frac{d^{2}}{a^{2}}+m_{2} \frac{d^{4}}{a^{4}}+m_{3} \frac{d^{6}}{a^{6}}\right\}-l_{0}+l_{1} \frac{d^{2}}{a^{2}} \\
& \left.+l_{2} \frac{d^{4}}{a^{4}}+l_{3} \frac{d^{6}}{a^{6}}\right],
\end{aligned}
\end{aligned}
$$

in which $m_{1}, m_{2}, m_{3}, l_{0}, l_{1}, l_{2}, l_{3}$ are functions of $\frac{c}{b}$ or $\frac{b}{c}$, which may be obtained from the table given by Lyle (B. S. Sci. Papers, No. 320, Tables $B$ and $C$, pp. 569-7o), and $d$ is the diagonal of the rectangular cross section, $d=\sqrt{b^{2}+c^{2}}$. Lyle's formula converges well enough to give an accuracy of one in ten thousand for values of $d$ as large as the mean diameter $2 a$. This con- 
dition gives the following relation between the parameters used in the tables,

$$
\left(\frac{c}{2 a}\right)^{2}\left[\mathrm{I}+\left(\frac{b}{c}\right)^{2}\right] \leqq \mathrm{I} .
$$

DWIGHT'S FORMULA FOR LONG, THIN coILS.-For calculating $k$ in $(4)$

$$
\begin{aligned}
& -k=-\frac{2}{3}\left(\frac{c}{2 a}\right)+\frac{\mathrm{I}}{3}\left(\frac{c}{2 a}\right)^{2}+\frac{\mathrm{I}}{3 \pi}\left(\frac{2 a}{b}\right)\left[\left\{\left(\frac{c}{2 a}\right)^{2}-\frac{\mathrm{I}}{20}\left(\frac{c}{2 a}\right)^{4}\right.\right. \\
& \left.\left.-\frac{23}{4480}\left(\frac{c}{2 a}\right)^{6}\right\} \log _{\mathrm{e}} \frac{4}{\frac{c}{2 a}}-\frac{23}{\mathrm{I} 2}\left(\frac{c}{2 a}\right)^{2}+\frac{\mathrm{I}}{400}\left(\frac{c}{2 a}\right)^{4}+\frac{\mathrm{I}}{35^{\circ}} \frac{4547}{35^{84}}\left(\frac{c}{2 a}\right)^{\circ}\right] \\
& +\left(\frac{c}{2 a}\right)^{2} \frac{2 a}{b}\left\{\frac{p}{6}-\frac{5}{24} p^{3}+\frac{p^{5}}{3}-\frac{95}{128} p^{7}+\frac{2 \mathrm{I} 7}{\mathrm{I} 28} p^{9}-\frac{2 \mathrm{I} 35}{5 \mathrm{I} 2} p^{11}\right. \\
& \left.+\frac{\mathrm{II} \times \mathrm{I961}}{2048} p^{13}-\frac{\mathrm{I} 3 \times 689 \mathrm{I} 5}{32768} p^{15}\right\}+\left(\frac{c}{2 a}\right)^{4} \frac{2 a}{b}\left\{\frac{p}{36}-\frac{\mathrm{I} 7}{\mathrm{I} 8 \mathrm{o}} p^{3}\right. \\
& \left.+\frac{53}{96} p^{5}-\frac{1265}{576} p^{7}+\frac{38857}{4608} p^{9}-\frac{3913}{128} p^{11}\right\}+\left(\frac{c}{2 a}\right)^{6} \frac{2 a}{b}\left\{-\frac{p^{3}}{120}\right. \\
& \left.+\frac{15}{\text { II } 2} p^{5}-\frac{\text { II } 17}{672} p^{7}+\frac{\text { II } 83}{96} p^{9} \ldots\right\} \text {, }
\end{aligned}
$$

in which

$$
p=\frac{1}{\sqrt{1+4\left(\frac{b}{2 a}\right)^{2}}}
$$

For an infinitely long coil, $\underline{2 a}=0, p=0$, and we have for the limiting value of $k$

$$
K=\frac{2}{3}\left(\frac{c}{2 a}\right)-\frac{1}{3}\left(\frac{c}{2 a}\right)^{2}
$$

which shows the maximum value of $k$ corresponding to a given value of $\frac{c}{2 a}$, when $\frac{c}{2 a}$ is small. From (I4), however, it is evident that when the approximate relation, $\log _{\mathrm{e}} \frac{c}{2 a} \geqq \log _{\mathrm{e}} 4-\frac{23}{\mathrm{I} 2}$, is satisfied, the term with the coefficient $\frac{\mathrm{r}}{3 \pi}$ changes sign, so that for values of $\frac{c}{2 a}$ greater than about 0.6 the maximum value of $d k$ comes for coils of finite length. In (I4) the quantity $p$ is always less than unity, but for rapid convergence the values of $\frac{c}{2 a}$ and $\frac{2 a}{b}$ 


\section{$4^{8} 4$}

Scientific Papers of the Bureau of Standards.

IVol. 18

must also both be small, which is the case only with thin coils with length greater than the mean diameter.

DWIGHT'S FORMULA FOR LONG, THICK COILS.-If we place $r=$ the outer radius, $s=$ the inner radius, then

$$
\begin{aligned}
L_{\mathrm{u}} & =0.002 \frac{\pi^{2} n^{2}}{b c^{2}}\left[\left(\frac{\mathrm{I}}{3} r^{4}-\frac{4}{3} r s^{3}+s^{4}\right)-\frac{\mathrm{I}}{b}\left(0.244 \mathrm{I} 272 r^{5}-\frac{2}{3} r^{2} s^{3}\right.\right. \\
& \left.+0.42 .77559 s^{5}+\frac{s^{5}}{\mathrm{IO}} \log _{\mathrm{e}} \frac{r}{s}\right)+\frac{s^{5}}{b}\left(0.004464 \frac{s^{2}}{r^{2}}+0.000543 \frac{s^{4}}{r^{4}}\right. \\
& \left.+0.000129 \frac{s^{8}}{r^{6}}+\ldots \ldots\right)+\frac{\mathrm{I}}{9 b^{2}}\left(r^{3}-s^{3}\right)^{2}-\frac{\mathrm{I}}{30 b^{4}}\left(r^{3}-s^{3}\right)\left(r^{5}-s^{5}\right) \\
& +\frac{\mathrm{I}}{84 b^{8}}\left(r^{3}-s^{3}\right)\left(r^{7}-s^{7}\right)+\frac{3}{200 b^{6}}\left(r^{5}-s^{5}\right)^{2}-\frac{5}{864 b^{8}}\left(r^{3}-s^{3}\right)\left(r^{9}-s^{9}\right) \\
& -\frac{3}{\mathrm{II} 2 b^{8}}\left(r^{5}-s^{5}\right)\left(r^{7}-s^{7}\right)+\ldots . .
\end{aligned}
$$

The general term in the power series in $\frac{s}{r}$ is

$$
\frac{(2 n-1) !(2 n+1) !}{n ! n !(n+1) !(n+2) !(2 n+5) 2^{4 n}} \frac{s^{2 n}}{r^{2 n}} \text {. }
$$

Writing $r=a\left(\mathrm{I}+\frac{c}{2 a}\right), s=a\left(\mathrm{I}-\frac{c}{2 a}\right)$, and factoring out $\frac{\mathrm{I}}{3} \cdot r^{4}$, this takes the form

in which

$$
L_{\mathrm{u}}=0.00 \mathrm{r} \frac{\pi^{2}}{6} \frac{n^{2} a^{2}}{b} \frac{\left(\mathrm{I}+\frac{c}{2 a}\right)^{4}}{\left(\frac{c}{2 a}\right)^{2}} Q
$$

$$
\begin{aligned}
Q & =\left(\mathrm{I}-4 \frac{s^{3}}{r^{3}}+3 \frac{s^{4}}{r^{4}}\right)-\frac{3 r}{b}\left(0.244 \mathrm{I} 27^{2}-\frac{2}{3} \frac{s^{3}}{r^{3}}+0.4277559 \frac{s^{5}}{r^{5}}\right. \\
& \left.+\frac{\mathrm{I}}{\mathrm{IO}} \frac{s^{5}}{r^{5}} \log _{\mathrm{e}} \frac{r}{s}\right)+3 \frac{s^{4}}{r^{4}} \frac{s}{b}\left(0.004464 \frac{s^{2}}{r^{2}}+0.000543 \frac{s^{4}}{r^{4}}+0.000 \mathrm{I} 29 \frac{s^{8}}{r^{6}}\right. \\
& +\ldots .)+\frac{\mathrm{I}}{3} \frac{r^{2}}{b^{2}}\left(\mathrm{I}-\frac{s^{3}}{r^{3}}\right)^{2}-\frac{\mathrm{I}}{\mathrm{IO}} \frac{r^{4}}{b^{4}}\left(\mathrm{I}-\frac{s^{3}}{r^{3}}\right)\left(\mathrm{I}-\frac{s^{5}}{r^{5}}\right) \\
& +\frac{\mathrm{I}}{28} \frac{r^{6}}{b^{6}}\left(\mathrm{I}-\frac{s^{3}}{r^{3}}\right)\left(\mathrm{I}-\frac{s^{7}}{r^{7}}\right)+\frac{9}{200}{\frac{r^{6}}{b^{6}}}^{\mathrm{s}}\left(\mathrm{I}-\frac{s^{5}}{r^{5}}\right)^{2} \\
& -\frac{5}{288} \frac{r^{8}}{b^{8}}\left(\mathrm{I}-\frac{s^{3}}{r^{3}}\right)\left(\mathrm{I}-\frac{s^{9}}{r^{9}}\right)-\frac{9}{\mathrm{II} 2} \frac{r^{8}}{b^{8}}\left(\mathrm{I}-\frac{s^{5}}{r^{5}}\right)\left(\mathrm{I}-\frac{s^{7}}{r^{7}}\right)+\ldots
\end{aligned}
$$


The quantity $K^{\prime}$ in equation (2) is related to $Q$ by the expression

$$
K^{\prime}=\frac{\left(\mathrm{I}+\frac{c}{2 a}\right)^{4}}{24\left(\frac{c}{2 a}\right)^{2}} Q
$$

The formula (16) takes the simple form

$$
\begin{gathered}
L_{\mathrm{u}}=0.001 \frac{8}{3} \pi^{2} \frac{n^{2} a^{2}}{b}\left[\mathrm{I}-0.73238 \mathrm{r} 6\left(\frac{2 a}{b}\right)+\frac{\mathrm{I}}{3}\left(\frac{2 a}{b}\right)^{2}-\frac{\mathrm{I}}{\mathrm{IO}}\left(\frac{2 a}{b}\right)^{4}\right. \\
\left.+\frac{\mathrm{II} 3}{1400}\left(\frac{2 a}{b}\right)^{6}-\frac{197}{2016}\left(\frac{2 a}{b}\right)^{8}+\ldots\right]
\end{gathered}
$$

for a zero inner radius (solid coil).

Both (I6) and (I9) converge only for coils where the length is greater than the outer radius.

BUTTERWORTH'S FORMULAS FOR THICK COILS.-These formulas are here adapted to the nomenclature of the formulas and tables of this paper. The quantity $K^{\prime}$ is more simply related to these formulas than $P^{\prime}$. The latter can be obtained from $K^{\prime}$ by the relation given below.

$K^{\prime}=\frac{\mathrm{I}}{24} \frac{\left(\mathrm{I}+\frac{c}{2 a}\right)^{4}}{\left(\frac{c}{2 a}\right)^{2}}\left[\left(\mathrm{I}-4 \frac{s^{3}}{r^{3}}+3 \frac{s^{4}}{r^{4}}\right)+3\left(\frac{2 a}{b}\right)\left(\mathrm{I}+\frac{c}{2 a}\right)(x-y)\right]$,

in which different formulas have to be used for the quantities $x$ and $y$ according to the length of the coil. Note that the first term of (20) agrees with the first term of (I 8).

The general formula for $x$ and $y$ may be written

$$
\begin{aligned}
& x=\xi\left(\frac{b}{r}, \mathrm{I}\right)-2 \frac{s^{3}}{r^{3}} \xi\left(\frac{b}{r}, \frac{s}{r}\right)+\frac{s^{5}}{r^{5}} \xi\left(\frac{b}{r} \cdot \frac{r}{s}, \mathrm{I}\right), \\
& y=\left(\mathrm{I}+\frac{s^{5}}{r^{5}}\right) \xi(\mathrm{O}, \mathrm{I})-2 \frac{s^{3}}{r^{3}} \xi\left(0, \frac{s}{r}\right),
\end{aligned}
$$

expressed in terms of the general function $\xi\left(\frac{b}{r}, \frac{s}{r}\right)$, for which Butterworth gives the expressions below in terms of the variables $z=\frac{b}{r}, \gamma=\frac{s}{r}$. 
1. For $z>4$,

$$
\begin{aligned}
2 z \xi(z, \gamma) & =\frac{\mathrm{I}}{9}-\frac{\mathrm{I}}{(2 z)^{2}}\left(\frac{\mathrm{I}}{\mathrm{I} 5}+\frac{\gamma^{2}}{\mathrm{I} 5}\right)+\frac{\mathrm{I}}{(2 z)^{4}}\left(\frac{2}{2 \mathrm{I}}+\frac{6}{25} \gamma^{2}+\frac{2}{2 \mathrm{I}} \gamma^{4}\right) \\
& -\left(\frac{\mathrm{I}}{2 z}\right)^{6}\left(\frac{5}{27}+\frac{6}{7} \gamma^{2}+\frac{6}{7} \gamma^{4}+\frac{5}{27} \gamma^{6}\right) \\
& +\frac{\mathrm{I}}{(2 z)^{5}}\left(\frac{\mathrm{I} 4}{33}+\frac{28}{9} \gamma^{2}+\frac{40}{7} \gamma^{4}+\frac{28}{9} \gamma^{8}+\frac{\mathrm{I} 4}{33} \gamma^{8}\right)-\ldots
\end{aligned}
$$

2. For $4>z>\gamma$,

in which

$$
\xi(z, \gamma)=A-(B-\alpha) \gamma^{2}+C \gamma^{4}-D \gamma^{0},
$$

$$
\begin{aligned}
3 A & =\frac{z^{2}}{2} \log _{\mathrm{e}} \frac{(\mathrm{I}+\zeta)}{z}+\frac{\zeta}{2}-z, \\
40 B & =\log _{\mathrm{e}} \frac{(\mathrm{I}+\zeta)}{z}-\frac{\mathrm{I}}{\zeta} \\
\mathrm{I} 344 C & =-\frac{\mathrm{I}}{\zeta}\left(\frac{\mathrm{I}}{\mathrm{I}+\zeta}+\frac{\mathrm{I}}{\zeta^{2}}-\frac{3}{\zeta^{4}}\right), \\
82944 D & =\frac{3}{\zeta}\left(\frac{\mathrm{I}}{(\mathrm{I}+\zeta)^{2}}-\frac{\mathrm{I}}{\zeta^{2}}-\frac{3}{\zeta^{4}}+\frac{35}{\zeta^{6}}-\frac{35}{\zeta^{8}}\right), \\
\zeta^{2} & =\mathrm{I}+z^{2}, \\
\alpha & =\left(\frac{z}{\gamma}\right)^{2} \sum_{2}^{\infty}-(-\mathrm{I})^{\mathrm{n}}(2 n-3) !\left(\frac{\gamma}{(2 n+3) n !(n+\mathrm{I}) !}\left(\frac{2 \mathrm{n}}{2 z}\right)^{2 \mathrm{n}} .\right.
\end{aligned}
$$

3. For $\gamma>z>0$,

$$
\begin{aligned}
\xi(z, \gamma) & =\left(\frac{z^{2}}{6}-\frac{\gamma^{2}}{40}\right) \log _{\mathrm{e}} \frac{\mathrm{I}}{\gamma}+A^{\prime}-\left(B^{\prime}-\beta\right) \gamma^{2}+C \gamma^{4}-D \gamma^{\circ} \\
3 A^{\prime} & =\frac{z^{2}}{2} \log _{\mathrm{e}} 2(\mathrm{I}+\zeta)+\frac{\zeta}{2}-z-\frac{z^{2}}{3} \\
40 B^{\prime} & =\log _{\mathrm{e}} 2(\mathrm{I}+\zeta)-\frac{\mathrm{I}}{\zeta}+\frac{29}{20} \\
\beta & =\frac{z}{2 \gamma}\left\{\frac{\mathrm{I}}{3}-\frac{\mathrm{I}}{3} \frac{z^{2}}{\gamma^{2}}+\frac{\mathrm{I}}{6} \frac{z^{3}}{\gamma^{3}}-\frac{\mathrm{I}}{30} \frac{z^{4}}{\gamma^{4}}\left(\log _{\mathrm{e}} \frac{2 \gamma}{z}+\frac{77}{60}\right)\right. \\
& \left.-\frac{z^{2}}{\gamma^{2}} \frac{8}{2} \frac{(-\mathrm{I})^{\mathrm{n}}(2 n-3) !}{2^{2 \mathrm{n}-2}(n-\mathrm{I}) !(n+\mathrm{I}) !(2 n+\mathrm{I})(2 n+3)} \frac{z^{2 \mathrm{n}}}{\gamma^{2 \mathrm{n}}}\right\}
\end{aligned}
$$

and $C$ and $D$ have the same values as in (23). 
Grover] Inductance of Circular Multilayer Coils.

4. For $z=0$

$$
\begin{aligned}
\xi(z, \gamma)_{\bullet} & =\frac{\mathrm{I}}{6}-\frac{\gamma^{2}}{40}\left(\log _{\mathrm{e}} \frac{4}{\gamma}+\frac{9}{20}\right)+\frac{\gamma^{4}}{2} \sigma, \\
\sigma & =\sum_{0}^{\infty}\left(\frac{\mathrm{I} \cdot 3 \cdot 5 \cdots(2 n+3)}{2 \cdot 4 \cdot 6 \cdots(2 n+4)}\right)^{2} \frac{\gamma^{2 n}}{(2 n+7)(2 n+3)(n+3)(n+\mathrm{I})} .
\end{aligned}
$$

LYLE'S FORMULA FOR NARROW DISK COILS, $(b=0)$.

$L=$ o.oor $n^{2} a P$

$$
\begin{array}{r}
P=4 \pi\left[\left(\log _{\frac{\mathrm{e}}{\frac{c}{c}}} \frac{4}{2 a}-\frac{\mathrm{I}}{2}\right)+\frac{\mathrm{I}}{24}\left(\frac{c}{2 a}\right)^{2}\left(\log _{\mathrm{e}} \frac{4}{\frac{c}{2 a}}+\frac{43}{\mathrm{I} 2}\right)+\frac{\mathrm{II}}{2880}\left(\frac{c}{2 a}\right)^{4}\right. \\
\left.\left(\log _{\frac{\mathrm{e}}{\frac{c}{2 a}}}+\frac{96}{55}\right)+\frac{\mathrm{IO} 3}{105} \frac{\mathrm{I}}{1024}\left(\frac{c}{2 a}\right)^{6}\left(\log _{\frac{\mathrm{e}}{\frac{4}{2 a}}}+\mathrm{I} . \mathrm{I} 394\right)\right]
\end{array}
$$

SPIELREIN'S FORMULA FOR WIDE DISK COILS, $(b=0)$.

$$
\begin{aligned}
P & =\frac{\left(\mathrm{I}+\frac{c}{2 a}\right)^{3}}{4\left(\frac{c}{2 a}\right)^{2}} S \\
S & =6.96957-\gamma^{3}\left(30.3008 \log _{10} \frac{\mathrm{I}}{\gamma}+9.08008\right) \\
& +\mathrm{x} .48044 \gamma^{5}+0.33045 \gamma^{7}+0.12494 \gamma^{9}+0.06038 \gamma^{11} \\
& +0.0337 \gamma^{13} \ldots
\end{aligned}
$$

WASHINGTON, June 27, I92I. 


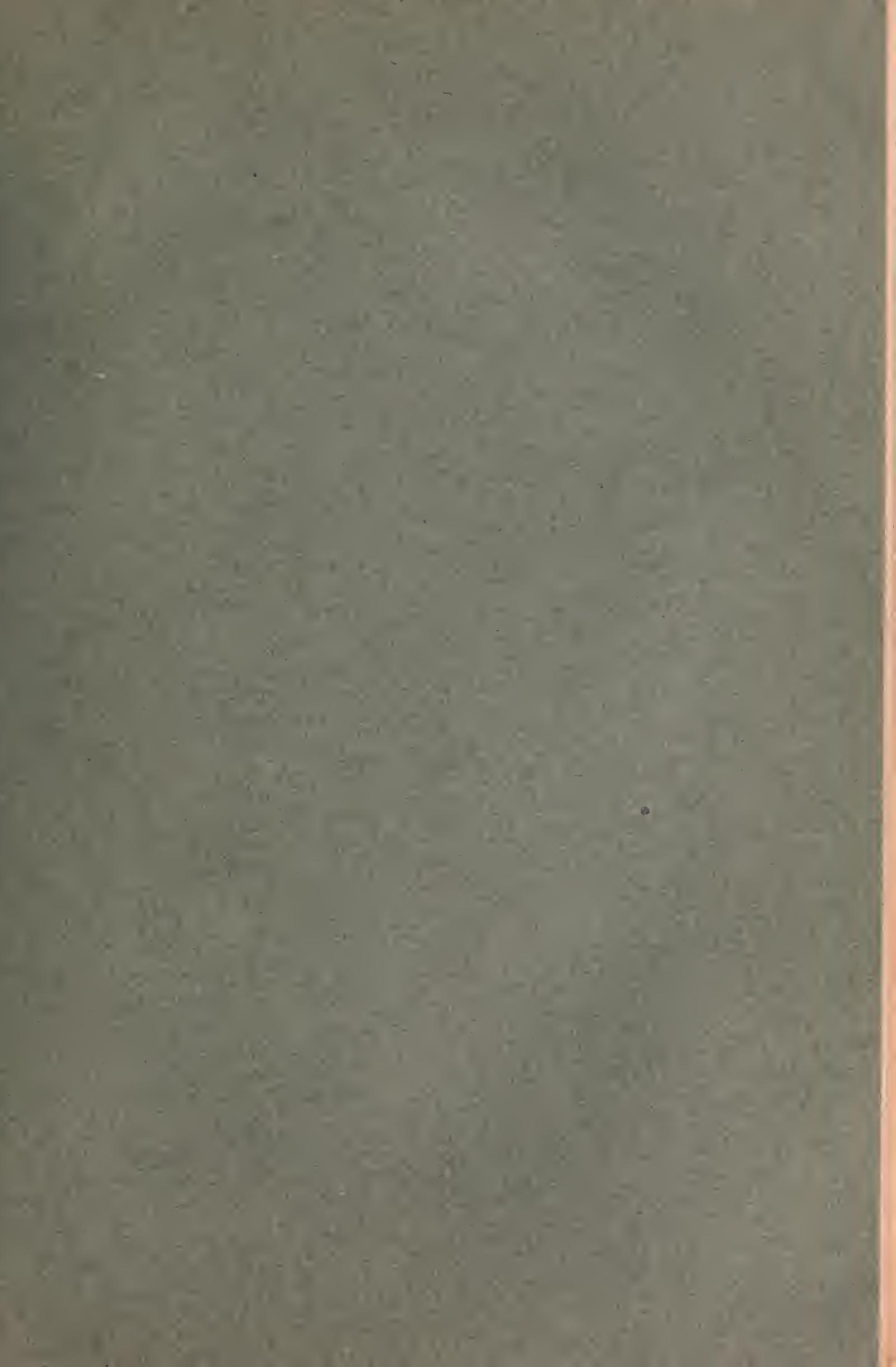


